\title{
Shark faunas from the Late Jurassic-Early Cretaceous of northeastern Thailand
}

\author{
Gilles Cuny • Romain Liard • Uthumporn Deesri • \\ Tida Liard · Suchada Khamha • Varavudh Suteethorn
}

Received: 13 August 2012/Accepted: 9 January 2013/Published online: 3 December 2013

(C) The Author(s) 2013. This article is published with open access at Springerlink.com

\begin{abstract}
A revision of the freshwater shark fauna from the Phu Kradung Formation in NE Thailand allows the recognition of a new species of Acrodus, which represents the youngest occurrence of the genus and confirms its displacement in freshwater environments after the Toarcian. The rest of the shark fauna includes teeth of Hybodus sp., aff. Hybodus sp., hybodontid dermal denticles, Jiaodontus sp., Lonchidion sp. A, Lonchidion sp. B, Heteroptychodus $\mathrm{cf}$. H. kokutensis and dorsal fin spines. The presence of Jaiodontus and of unusual hybodontid dermal denticles suggests a Jurassic age for most of the Phu Kradung Formation, whereas the presence of Heteroptychodus suggests an Early Cretaceous age for the top of the Formation. However, the age of the Phu Kradung Formation is still uncertain, with contradictory signals coming from palynology, detrital zircon thermochronology and vertebrate palaeontology. In any case, it appears that
\end{abstract}

\section{G. Cuny $(\bowtie)$}

The Natural History Museum of Denmark,

Øster Voldgade 5-7, 1350, Copenhagen K, Denmark

e-mail: gilles@snm.ku.dk

\section{R. Liard · T. Liard}

Sirindhorn Museum, Sahatsakhan, Kalasin 46140,

Thailand

e-mail: tidaromain@gmail.com

T. Liard

e-mail: tidaromain@gmail.com

\section{U. Deesri · S. Khamha · V. Suteethorn}

Palaeontological Research and Education Centre,

Mahasarakham University, Mahasarakham 44150,

Thailand

e-mail: uthumporn_deesri@yahoo.com

S. Khamha

e-mail: skhamha@yahoo.com this is the oldest occurrence of the genus Heteroptychodus, and suggests a Thai origin for this genus, which may have replaced Acrodus in the Thai freshwater palaeoecosystems. Together with Acrodus, the presence of Lonchidion sp. A suggests some European affinities for the shark fauna from the Phu Kradung Formation.

Keywords Southeast Asia $\cdot$ Mesozoic $\cdot$ Khorat Group · Hybodontiformes · Freshwater sharks

Kurzfassung Die Revision der Süßwasser-Haifauna von der Phu Kradung Formation in NO-Thailand führt zur Identifikation einer neuen Art von Acrodus, die den jüngsten Nachweis dieser Gattung darstellt und ihre Verdrängung in Süßwasser-Ökosystemen nach dem Toarc bestätigt. Die weitere Haifauna beinhaltet Zähne von Hybodus sp., aff. Hybodus sp., dermale Dentikel von Hybodontiden, Jiaodontus sp., Lonchiodon sp. A, Lonchiodon sp. B., Heteroptychodus cf. H. kokutensis und dorsale Flossenstachel. Das Vorkommen von Jiaodontus und von ungewöhnlichen hybodontiden dermalen Dentikeln deutet auf ein jurassisches Alter für den größten Teil der Phu Kradung Formation hin, während der Nachweis von Heteroptychodus ein unterkretazisches Alter für den obersten Teil der Formation andeutet. Allerdings bleibt das Alter der Phu Kradung Formation unsicher, da palynologische Daten, detritale Zirkone und die Wirbeltierpaläontologie widersprüchliche Resultate ergeben. Allerdings dürfte dies auf jeden Fall den ältesten Nachweis von Heteroptychodus darstellen und somit einen thailändischen Ursprung dieser Gattung andeuten, die Acrodus in den Süßwasser-Ökosystemen Thailands verdrängt haben mag. Zusammen mit Acrodus deutet das Vorkommen von Lonchiodon sp. A auf einen europäischen Einfluss auf die Haifauna der Phu Kradung Formation hin. 
Schlüsselwörter Südost-Asien · Mesozoikum · Khorat-Gruppe · Hybodontiformes · Süßwasser-Haie

\section{Insitutional abbreviations}

SM Sirindhorn Museum, Sahatsakhan, Kalasin Province

PRC Palaeontological Research and Education Centre, Mahasarakham University

\section{Introduction}

Since 1990, the Khorat Group (Late Jurassic-Early Cretaceous in age) has yielded rich assemblages of freshwater hybodont sharks, which were recovered from three formations (from bottom to top): the Phu Kradung, Sao Khua and Khok Kruat Formations (Cuny et al. 2007). The assemblages from the Sao Khua and Khok Kruat Formations are well known and show a high level of endemicity (Cuny et al. 2006, 2008, 2010), whereas the Phu Kradung Formation has so far yielded mostly fragmentary remains that have proven difficult to interpret (Cuny et al. 2007). In 2008, the discovery of a new locality in Kalasin Province, Phu Noi, led to the discovery of shark teeth in conglomeratic sandstones of the Phu Kradung Formation, the preservation of which was better than at any other sites discovered in this formation so far. This new material facilitated the reappraisal of the whole of the shark faunas from the Phu Kradung Formation and allowed a better understanding of their composition.

\section{Geological setting}

The Phu Kradung Formation is the most basal formation of the Khorat Group (Racey and Goodall 2009). Its thickness varies from $1,200 \mathrm{~m}$ in the basin centre to around $500 \mathrm{~m}$ on its southern flanks (Racey 2009). It consists of fluvial sandstones, siltstones and mudstones, and is dated as either Late Jurassic based on fossil vertebrate evidence (Buffetaut et al. 2001; Buffetaut and Suteethorn 2007; Tong et al. 2009a) or Early Cretaceous on the basis of palynology (Racey and Goodall 2009) and detrital zircon thermochronology (Carter and Bristow 2003). The Formation can be divided into a lower and an upper part, with sandstones tending to be more common in the upper than in the lower part (Sattayarak 1983; Racey et al. 1996). The lower part corresponds to a lake margin, whereas the upper part corresponds mostly to meandering river environments under a probable two-season semi-arid/humid climate (Mouret 1994; Racey et al. 1996; Racey 2009). However, a lower and an upper member have not yet been officially established, although the uppermost part is sometimes considered a separate formation, the Waritchaphum Formation (Mouret 1994; Philippe et al. 2004). All of the sites listed below are located in the upper part of the Phu Kradung Formation (Fig. 1).

The material described in the present work comes from eight localities (Fig. 2). Due to the Department of Mineral Resources' policy of protecting fossiliferous sites, the exact locations of the outcrops cannot be provided in this article. For scientific purposes, their GPS coordinates can be obtained on request from the Sirindhorn Museum. Phu Noi is located in Kham Muang District in Kalasin Province. This site encompasses three fossiliferous layers inside a complex palaeochannel sequence and its associated drainage system (Fig. 3):

- A light grey conglomeratic sandstone layer at the base of the palaeochannel, which yielded shark teeth and dermal denticles, scales and teeth of actinopterygians, fragments of lungfish toothplates and turtle shells, crocodile teeth and many indeterminate bone fragments. This layer is referred to here as PNA.

- A series of siltstone and mudstone higher up in the palaeochannel, approximately $10 \mathrm{~m}$ above the basal conglomeratic sandstone, which have yielded hybodont teeth, dermal denticles and finspines, as well as actinopterygian, turtle, crocodile and dinosaur fossils. This layer is referred to here as PNB.

- A greyish siltstone inside the proximal floodplain deposit. This layer is referred to here as PNC, and is situated approximately $400 \mathrm{~m}$ WSW of PNB. It has yielded hybodont dermal denticles, numerous Lepidotes-like scales and some fragments of crocodiles and dinosaurs.

The second site, Khok Sanam, is also located in Kham Muang district. It consists of bluish and purple siltstones that outcrop over a surface of $200 \mathrm{~m}^{2}$. The bluish siltstone yielded hybodont teeth and finspines, scales of actinopterygians, toothplates of lungfishes as well as turtle, crocodile and dinosaur remains.

Sang Khae is the third site located in Kham Muang district. It consists of green and purple siltstones that outcrop over a surface of $100 \mathrm{~m}^{2}$, but only a thin, $5 \mathrm{~cm}$ thick, green layer has yielded hybodont teeth, various actinopterygian scales, isolated teeth and jaw fragments, fragments of turtle shells, a possible lepidosaurian jaw fragment, and crocodile teeth.

Phu Nam Jun (Kuchinarai district, Kalasin province) has yielded a single shark tooth, recovered from greenish to reddish siltstones, which yielded many complete semionotiform fishes as well as a lungfish (Cavin et al. 2003b, 2007; Cavin and Suteethorn 2006). The tooth was found in a plaster jacket containing Lepidotes buddhabutrensis specimens. 


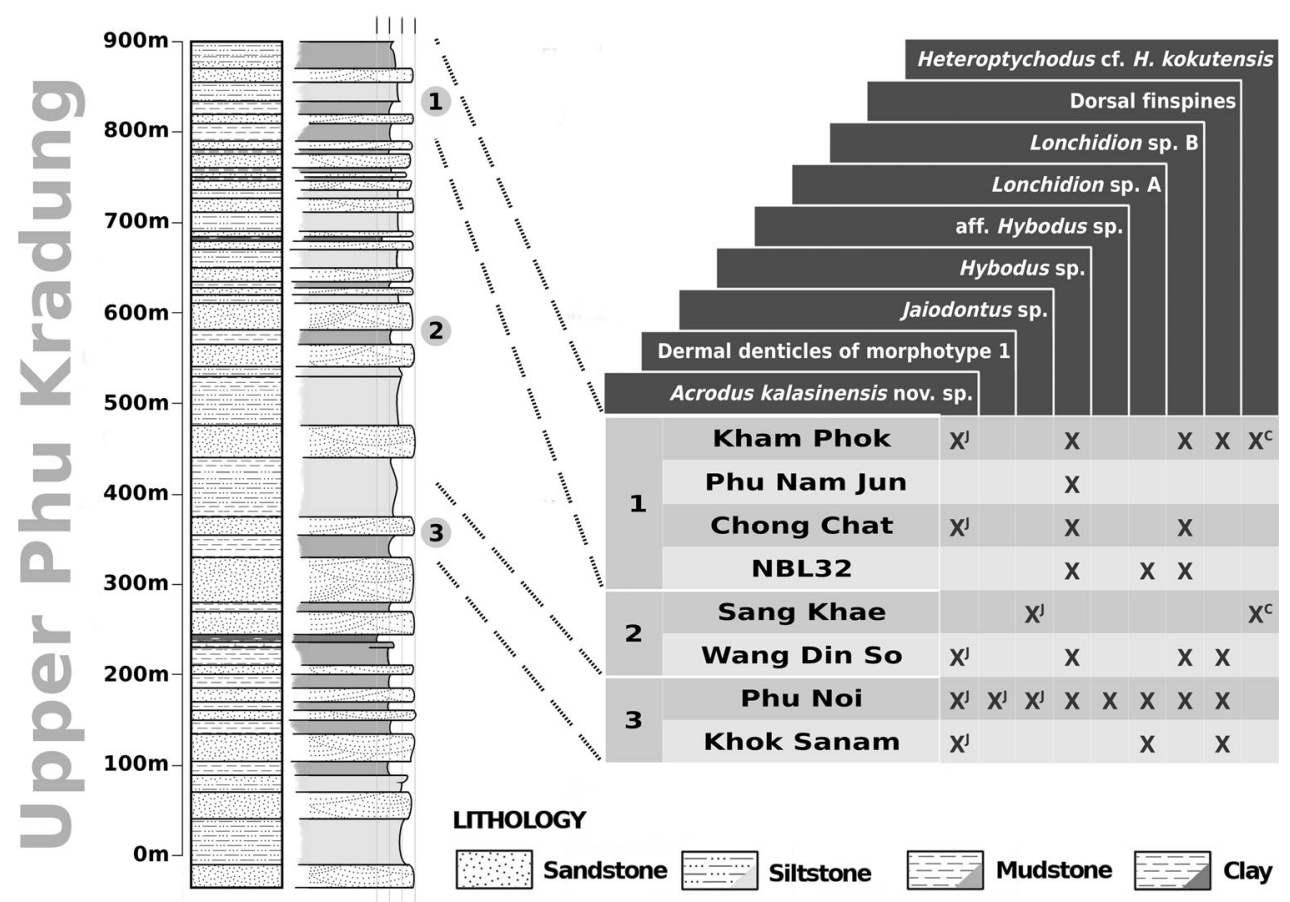

Fig. 1 Left: composite $\log$ of the upper part of the Phu Kradung Formation. The upper part, zone 1, corresponds to the upper twothirds of Mouret's (1994) Waritchaphum Formation and encompasses four sites. The middle part, zone 2, is approximately $500 \mathrm{~m}$ thick and encompasses the lower third of the Waritchaphum Formation. The lower part, zone 3 , is approximately $100 \mathrm{~m}$ thick and encompasses

Kham Phok is situated north of the village of Ban Kham Phok, Khamcha-i district, Mukdahan province. The shark teeth were recovered from a reddish siltstone level with sandy to microconglomeratic lenses, which was surface collected. The site has yielded a large fossil turtle as well as a theropod tibia (Buffetaut and Suteethorn 2007; Tong et al. 2009b). Fragments of hybodont finspines as well as teeth of actinopterygians, crocodiles and theropod dinosaurs were also recovered.

The fossils from Chong Chat (Non Sang district, Nong Bua Lamphu province) were recovered from greyish to reddish siltstones with intercalated detritic lenses. In addition to the shark teeth described below, the site has yielded actinopterygian scales and teeth, turtle shell fragments, crocodile remains, including cf. Theriosuchus, theropod bones and teeth as well as a possible hypsilophodontid tooth (Cavin et al. 2009; Lauprasert et al. 2011).

The second site in Nong Bua Lamphu province is located at the level of km 32 along Highway 210, between Nong Bua Lamphu and Udon Thani in Mueang district. The road bank cuts through a palaeochannel approximately $15 \mathrm{~m}$ wide, at the base of which is a reddish brown conglomeratic sandstone layer that has yielded hybodont teeth, teeth, scales and hemisegments of lepidotrichia of bony two sites. Right: distribution of the different taxa in the sites of the Phu Kradung Formation included in the present study. $\mathrm{X}^{\mathrm{J}}$ indicates genera normally unknown in the Cretaceous, whereas $\mathrm{X}^{\mathrm{c}}$ indicates genera normally restricted to the Cretaceous.The exact position of Kham Phok, NBL32 and Sang Khae in the log cannot be ascertained, whereas the one of Wang Din So is highly speculative

fishes, an incomplete crocodile tooth, as well as many unidentifiable small bone fragments. This site is referred to here as NBL32.

The last locality, Wang Din So, is a disused quarry (Wang Thong district, Phitsanulok province). The remnant of the front of the quarry is made of a $15 \mathrm{~m}$ high cliff consisting of a coarse grey sandstone surmounted by a 6-m-high series of intercalating grey siltstones and sandstones. The coarse basal sandstone yielded hybodont teeth and finspines, semionotiform teeth and scales, lungfish toothplates, as well as turtle and crocodile remains.

Correlation of sites situated in a non-marine formation is always problematic due to a lack of microfossils and frequent lateral changes of facies. Hence, the relative positions of the eight sites mentioned above are difficult to decipher, especially because the sediments dip at low angles (less than $10^{\circ}$ ), and the rather flat Khorat Plateau does not offer many good sections. However, Phu Nam Jun, Chong Chat, Kham Phok, and NBL32 are situated closer to the boundary with the Phra Wihan Formation than Phu Noi and Khok Sanam, and are thus slightly younger than those two (Liard and Martin 2011). Sang Khae is situated in between the two abovementioned sets of sites. Wang Din So is the most difficult site to correlate, as it is situated west of the Khorat Plateau, separated from the 
Fig. 2 Map of northeastern Thailand indicating the locations of the eight sites included in this study and outcrops of the Phu Kradung Formation
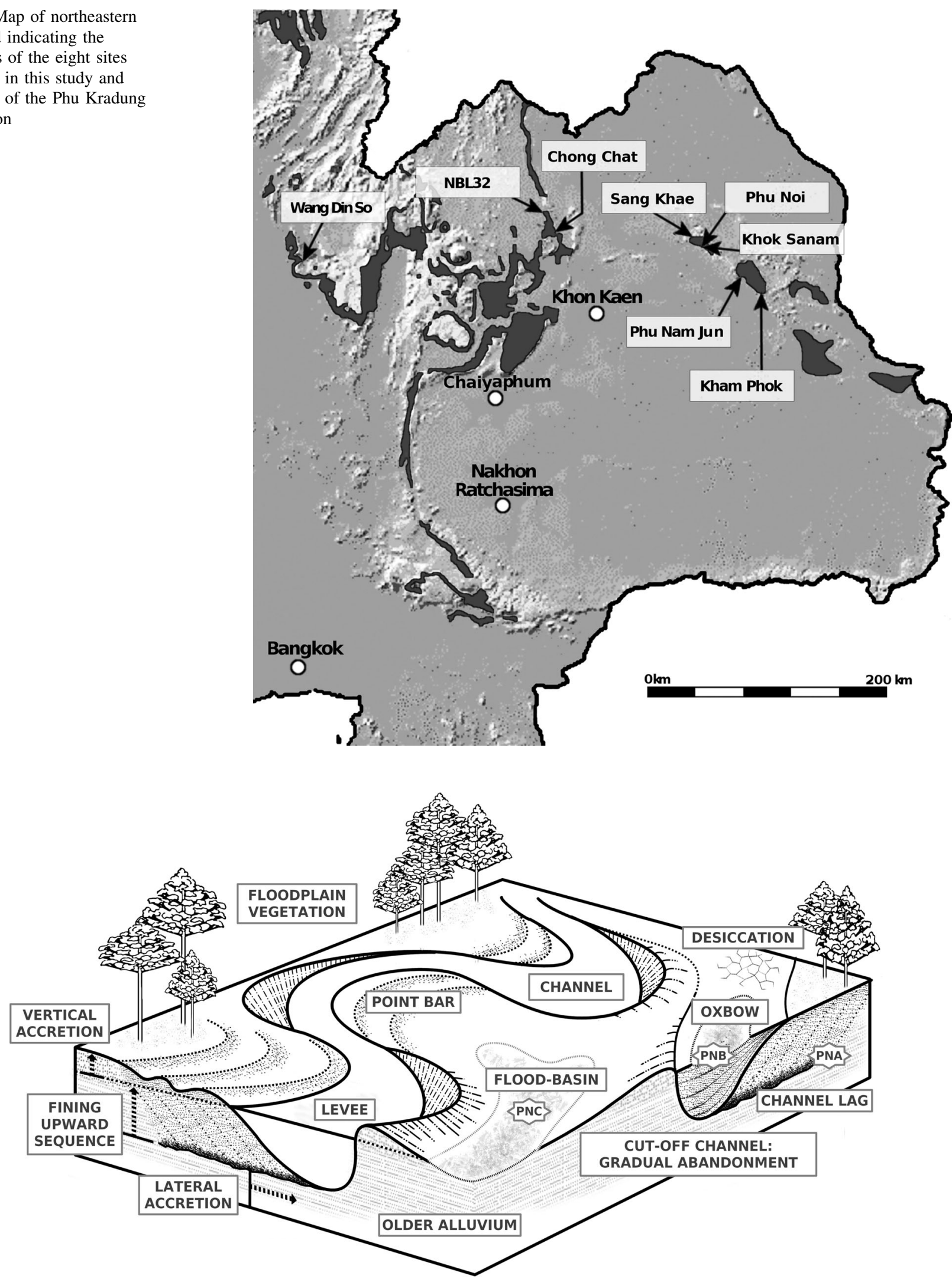

Fig. 3 Block diagram presenting the different depositional environments associated with the Phu Noi bone bed (PNB). PNA corresponds to a channel lag deposit, PNB to an abandoned channel, and PNC to a floodplain/backswamp deposit (from Boggs 1987). Silhouettes of the trees from Philippe et al. (2009) 
latter by the Loei-Petchabun and Sukothai foldbelts (Racey 2009; Department of Mineral Resources 2010). This site is considered part of the Phu Kradung Formation (Department of Mineral Resources 2001), and the presence of the massive sandstones in which the fossils have been found probably indicates that the site belongs to the upper part of the Formation, like the other seven sites. Whether it is younger or older than them is, however, impossible to say given the current state of our knowledge.

\section{Materials and methods}

Many of the fossils described in this work were recovered from screen-washing residues. Between 2001 and 2012, $830 \mathrm{~kg}$ of sediment from Chong Chat, $100 \mathrm{~kg}$ from Khok Sanam, $100 \mathrm{~kg}$ (mostly coming from plaster jackets) from Phu Nam Jun, $200 \mathrm{~kg}$ from Kham Phok, $170 \mathrm{~kg}$ from Sang Khae, and $290 \mathrm{~kg}$ from Phu Noi were processed. After collection, the sediment was left in water for at least $24 \mathrm{~h}$ before being screen-washed using sieves with a mesh size of $0.5 \mathrm{~mm}$. The residue was then left to dry and separated into two sets using sieves with a mesh size of 2 or $2.36 \mathrm{~mm}$. The fraction coarser than $2 \mathrm{~mm}$ was sorted at the Sirindhorn Museum or at Mahasarakham University with the naked eye, and all fossils were hand-picked. The fraction between 0.5 and 2 (or 2.36) $\mathrm{mm}$ was treated for $12 \mathrm{~h}$ in $10 \%$ formic acid, rinsed, dried, and the fossils were picked up under a binocular microscope. The soft sediment from Phu Noi (coming from PNB and PNC) yielded only a few vertebrate microremains, and the majority of the fossils came from the conglomeratic sandstone PNA. Blocks of this sandstone were treated using $10 \%$ formic acid and the residue was screen-washed using sieves with a $0.5 \mathrm{~mm}$ mesh. The process was repeated several times until approximately $3 \mathrm{~kg}$ of sandstone were treated. Half a kilogram of conglomeratic sandstone from NBL32 was processed the same way. The residue was then sorted under a binocular microscope. The fossils from the indurated sandstone of Wang Din So were collected and mechanically prepared by an avocational palaeontologist, Paladej Srisuk.

For imaging, most specimens were mounted on aluminium stubs using a gluestick or double-sided adhesive conductive carbon discs, coated with gold and photographed using a JEOL JSM-6460 LV SEM under an acceleration voltage of $10 \mathrm{kV}$ at Mahasarakham University, or a JEOL JSM-6335F SEM under an acceleration voltage of $7 \mathrm{kV}$ at the Natural History Museum of Denmark. The specimens in Fig. 3 were photographed using a binocular microscope fitted with a digital microscope camera (a Nikon SMZ1000 fitted with a Nikon Digital Sight DS-Fi1 at Sirindhorn Museum, and an Olympus
SZ40 fitted with an Olympus DP12 at the Natural History Museum of Denmark), whereas the hybodont finspines were photographed using a Canon G11 digital camera set in macro mode.

\section{Systematic palaeontology}

Class Chondrichthyes Huxley, 1880

Cohort Euselachii Hay, 1902

Order Hybodontiformes Patterson, 1966

Family Hybodontidae Owen, 1846

Subfamily Hybodontinae Owen, 1846 sensu Maisey, 1989

Genus Hybodus Agassiz, 1837

Hybodus sp.

Figure $4 \mathrm{a}-\mathrm{h}$

Material PNA: One broken but almost complete tooth (SM2012-1-002) and 40 fragmentary crowns, including SM2012-1-003. PNB: Two teeth and 13 fragmentary crowns. Kham Phok: Eight fragmentary crowns. Phu Nam Jun: One fragmentary crown. Chong Chat: 34 fragmentary crowns. NBL32: Two incomplete crowns. Wang Din So: 82 more or less complete teeth.

Description The teeth display a main cusp flanked by up to three cusplets mesially and two distally (Fig. 4a, b). SM2012-1-002 measures $7 \mathrm{~mm}$ mesio-distally, $2 \mathrm{~mm}$ labio-lingually and is $2.5 \mathrm{~mm}$ high, but the main cusp is broken around mid-height. In mesial or distal view, the labial face of the main cusp is slightly convex, whereas the lingual one is almost flat. There are up to 10 ridges per cusp, sometimes anastomosing in the lower part of the crown. They show a similar density on the labial and lingual sides, but they are stronger on the labial side. They originate from the apex of the cusps and cusplets and almost reach the base of the crown on both labial and lingual sides. Short ridges are sometimes present in the lower third of the crown (Fig. 4h). Some teeth from Phu Noi and Kham Phok appear almost smooth, but this is likely due to post-mortem wear, and they are tentatively included in the same taxon as the other teeth (contra Cuny et al. 2010). There is a moderately developed longitudinal crest, which is uninterrupted between cusp and cusplets. The cusp and cusplets have a nearly circular base in apical view in anterior teeth, whereas the main cusp is more compressed labio-lingually in lateral and posterior teeth.

The root is projected lingually, with a flat basal face. It is very porous, with foramina scattered all over its surface. The foramina have a tendency to be larger basally than close to the crown, both lingually and labially (Fig. 4a-d).

Comparison The teeth from the Phu Kradung Formation agree with those of the type species of Hybodus, $H$. 

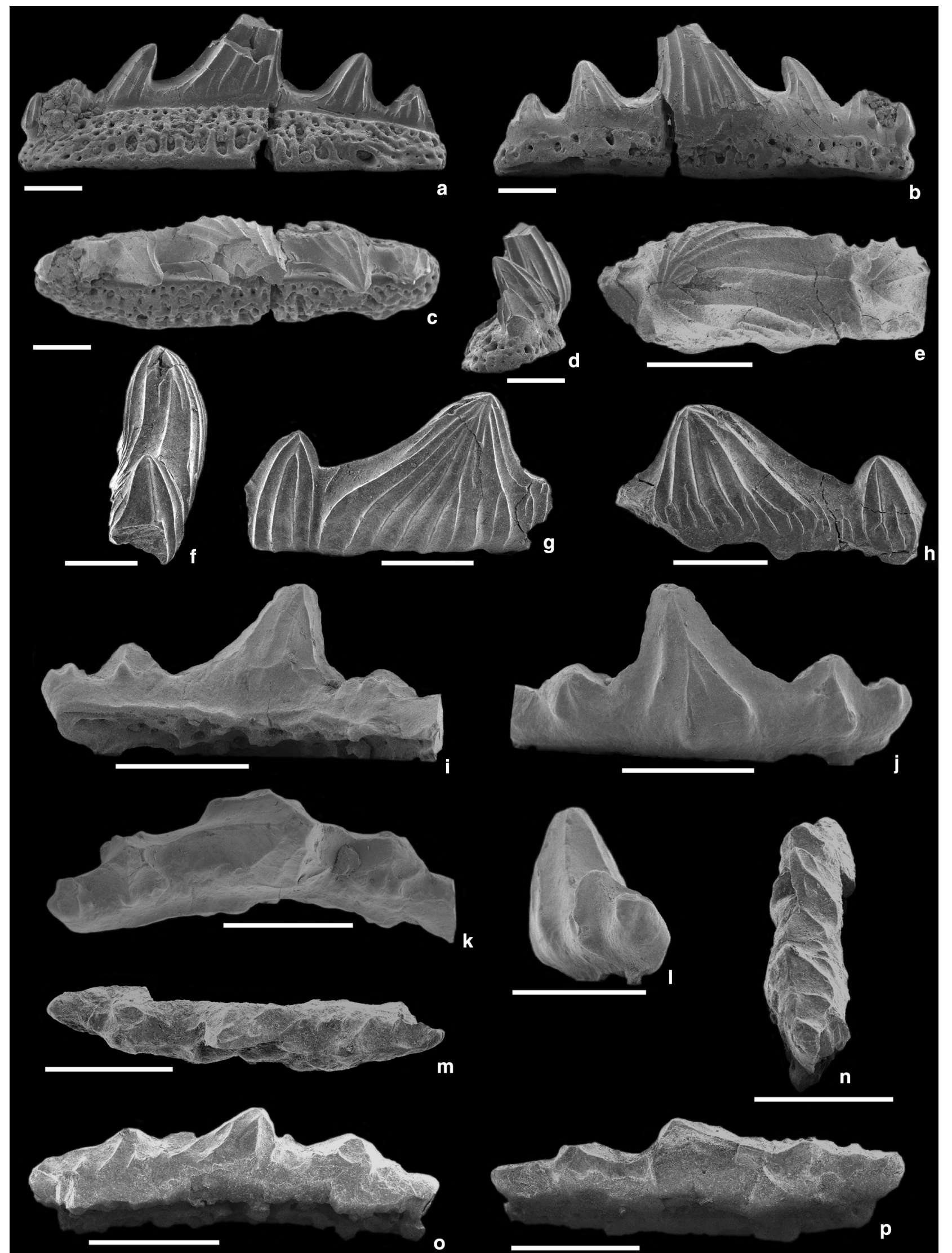
4 Fig. 4 a-h Hybodus sp. a-d SM2012-1-002 in a lingual, b labial, c apical and d distal views. e-h SM2012-1-003 in e apical, f mesial, $\mathbf{g}$ labial and $\mathbf{h}$ lingual views. $\mathbf{i}-\mathbf{p}$ aff. Hybodus sp. $\mathbf{i}-\mathbf{l}$ anterior tooth SM2012-1-004 in i lingual, $\mathbf{j}$ labial, $\mathbf{k}$ apical and $\mathbf{l}$ mesial views. $\mathbf{m}-$ p Posterior tooth SM2012-1-005 in $\mathbf{m}$ apical, $\mathbf{n}$ apico-mesial, o labial and p lingual views. All scale bars represent $1 \mathrm{~mm}$

reticulatus Agassiz, 1837, in possessing slender and sharply pointed cusp and cusplets, which are recurved distally and lingually and ornamented by numerous ridges (Maisey 1987). The Thai teeth are therefore attributed to this genus. They can, however, be easily separated from those of the type species because they possess a coarser ornamentation attaining the apex of cusp and cusplets (Maisey 1987). They are quite similar to those described from the Bathonian-Callovian Khlong Min Formation in southern Thailand. The pattern of ornamentation is, however, different, with the ridges rarely attaining the apex of cusps and cusplets in the latter (Cuny et al. 2009). As mentioned elsewhere (Cuny et al. 2010), Hybodus teeth from the Phu Kradung Formation are similar to those found on Kut Island. "Hybodus" sp. A from the Sao Khua Formation, which is likely to belong in fact to Egertonodus, is easily separated from the teeth from the Phu Kradung Formation by its ornamentation restricted to the lower part of the crown and the sigmoidal curvature of the main cusp in mesial or distal view (Cuny et al. 2006). The teeth of Hybodus sp. B from the Sao Khua Formation are more heavily built than those from the Phu Kradung Formation (Cuny et al. 2006). Hybodus aequitridentatus from the Khok Kruat Formation is easily separated from Hybodus sp. from the Phu Kradung Formation by its more complex crown ornamentation (Cuny et al. 2008).

The teeth from the Phu Kradung Formation are similar to the teeth of $H$. huangnidanensis (which is probably a junior synonym of $H$. antingensis, see Shang et al. 2008) from the Middle Jurassic of Southern China and to those of Hybodus cf. H. huangnidanensis from the Oxfordian of Northwest China, showing a similar shape and ornamentation pattern. The Chinese teeth can, however, be separated from the Thai ones as the latter possess a longitudinal crest that is not interrupted between cusp and cusplets, and there is no bulge at the base of the ridges ornamenting the crown (Wang 1977; Klug et al. 2010). The Thai teeth are also similar to those of Hybodus sp. from the Middle Jurassic of Hubei province in China. The latter separate from the Thai teeth by their first pair of cusplets widely separated from the main cusp (Shang et al. 2008).

The status of the Jurassic and Cretaceous Thai Hybodontinae remains quite unclear for the time being. Various species are present: at least one species in the Khlong Min Formation, another one in the Phu Kradung Formation (which may be the same as the one from Kut Island), one more species that probably does not belong to Hybodus in the Phu Kradung Formation (see below), one Hybodus and one Egertonodus species from the Sao Khua Formation, and $H$. aequitridentatus from the Khok Kruat Formation. Except for this last species, these Hybodontinae are known from fragmentary isolated teeth, which make assessment and comparison of intraspecific variations and heterodonty patterns difficult. If one also notes the fact that the genus Hybodus is badly in need of revision (Rees 2008), the naming of these different Thai species is deemed unwise until more complete teeth are found.

\section{aff. Hybodus sp.}

Figure $4 \mathrm{i}-\mathrm{p}$

Material PNA: One almost complete anterior crown (SM2012-1-004) and a complete posterior tooth (SM20121-005).

Description SM2012-1-004 displays two pairs of lateral cusplets (Fig. 4i, j). Cusp and cusplets have a somewhat pyramidal shape. It measures $3 \mathrm{~mm}$ mesio-distally, $1 \mathrm{~mm}$ labio-lingually and is $1.5 \mathrm{~mm}$ high. In apical view, it is arched lingually (Fig. 4k). The cusp and lateral cusplets are triangular in outline in labial or lingual view. The main cusp is asymmetric and slightly slanted distally. There are three anastomosing ridges on the labial face of the main cusp and four on its lingual face. The lingual ones are less developed than the labial ones. The lateral cusplets show one or two ridges labially, forming a node at the base of the crown and a single one lingually, dividing basally. There is a longitudinal crest, which is uninterrupted between the cusp and lateral cusplets.

SM2012-1-005 is devoid of nodes and possesses a lower cusp and lower cusplets than the crown described above (Fig. 4m-p). The main cusp is asymmetric and slightly slanted distally. The tooth measures $3.1 \mathrm{~mm}$ mesio-distally, $1.1 \mathrm{~mm}$ labio-lingually, and is $0.6 \mathrm{~mm}$ high. There is a longitudinal crest, which is uninterrupted between the cusp and lateral cusplets. The ridges ornamenting the crown anastomose in a way similar to the one seen on the crown described above, and the labial ornamentation is better developed than the lingual one. The root is narrow labio-lingually, more than the crown, and approximately half the height of the latter. It does not project lingually, and shows rather large foramina that are randomly distributed on its surface.

Comparison The lack of a well-developed labial peg at the base of the main cusp and of irregular, horizontal ridges near the base of the crown separates these two teeth from those of Jiaodontus from the Oxfordian of Northwest China (Klug et al. 2010). With their rather low, pyramidal cusp and cusplets showing labial nodes in anterior teeth, these teeth would probably have been attributed to "Polyacrodus" in the past. Rees (2008), however, 
demonstrated that "Polyacrodus" cannot be diagnosed on dental characters, and therefore all species currently identified as "Polyacrodus" should be referred to Hybodus, awaiting a revision of the latter genus. This is why we attribute SM2012-1-004 and SM2012-1-005 to aff. Hybo$d u s$. They probably represent a different genus, but the material available does not permit its erection for the time being. We tentatively consider these two teeth to represent the anterior and posterior teeth of the same species, but only the discovery of more material will allow this hypothesis to be tested.

Subfamily Acrodontinae Casier, 1959 sensu Maisey, 1989

Genus Acrodus Agassiz, 1837

Acrodus kalasinensis nov. sp.

Figures 5, 6a-h

Derivation of name from Kalasin Province, where the holotype was found.

Holotype SM2012-1-009, from PNA.

Paratypes SM2012-1-006-8, SM2012-1-010 and PRC63 from PNA.
Additional material PNA: 28 fragmentary crowns. Khok Sanam: one fragmentary crown. Kham Phok: one fragmentory crown. Chong chat: two fragmentary crowns. Wang Din So: Two complete teeth (PRC81 and PRC82) and one incomplete one.

Type locality Phu Noi hill, near Din Ji Village, Kham Muang District, Kalasin Province. Exact coordinates can be obtained on request from the Sirindhorn Museum, Sahatsakhan, Kalasin Province.

Type stratum a light grey conglomeratic sandstone layer at the base of Phu Noi Hill, in the Phu Kradung Formation.

Diagnosis Species of Acrodus characterized by small teeth, narrow labio-lingually, and showing a coarse, complex ornamentation of anastomosing ridges. The longitudinal crest is displaced labially and may attain the labial edge of the apical face. It is sometimes doubled lingually in anterior and lateral teeth. The ornamentation extends on the labial face, whereas the lingual one remains smooth.

Description The teeth are narrow labio-lingually and elongated mesio-distally, with a low profile. The holotype SM2012-1-009, a complete tooth, measures $7 \mathrm{~mm}$ mesiodistally, $2 \mathrm{~mm}$ labio-lingually, and is $2.5 \mathrm{~mm}$ high. The
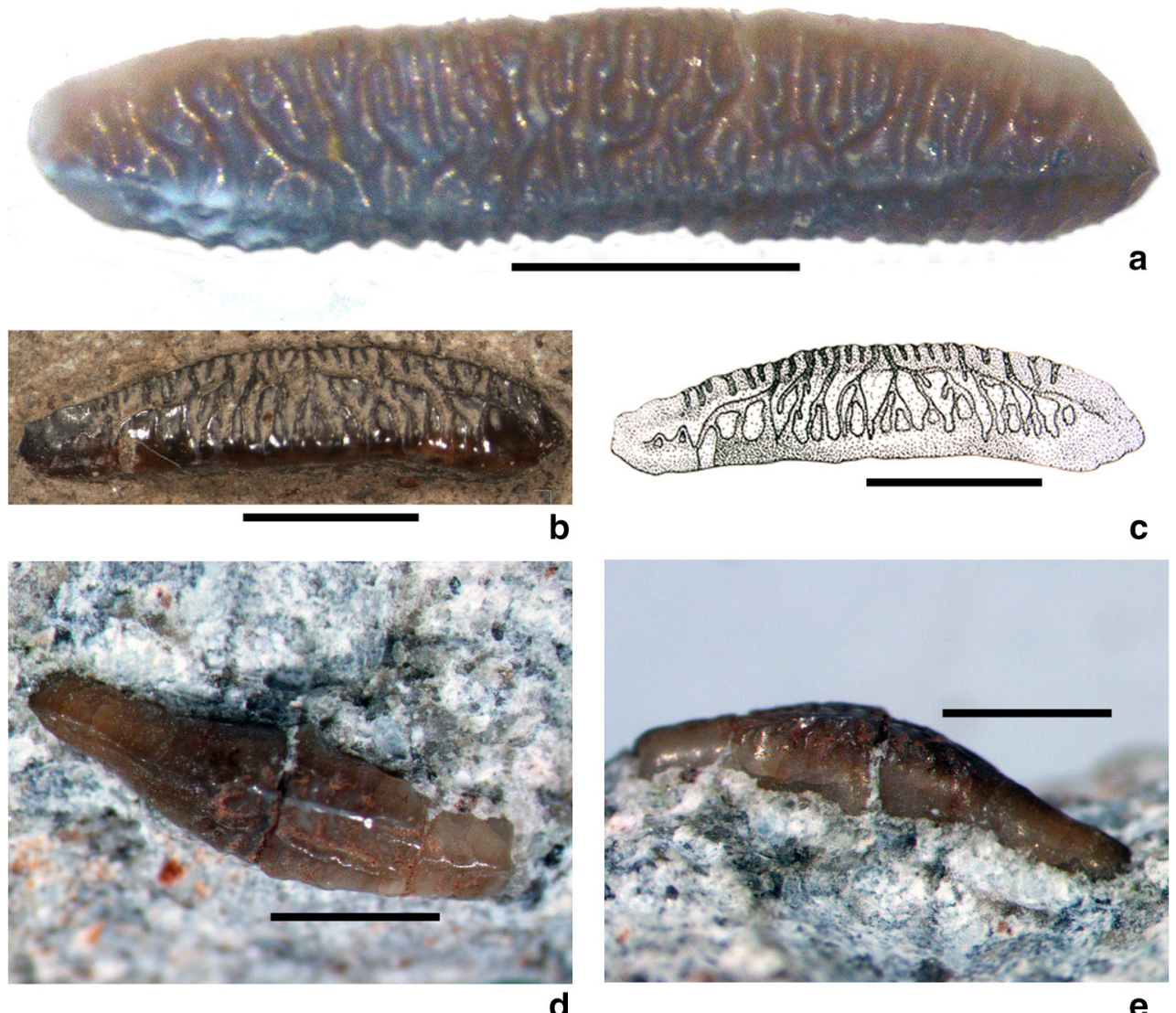

\section{,}

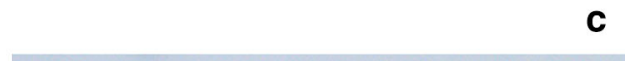

d

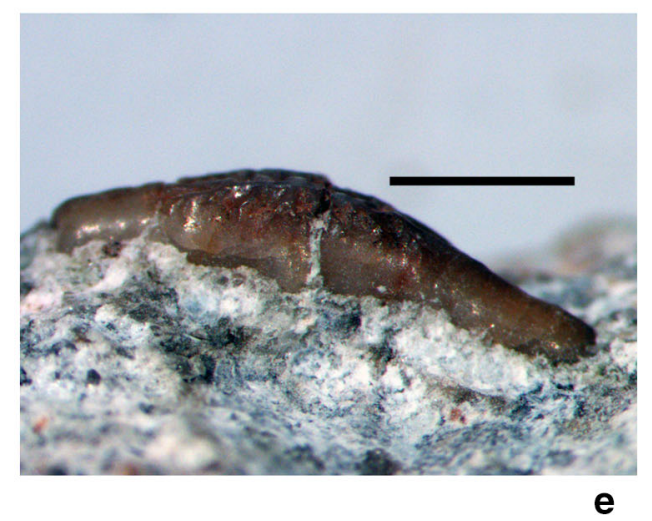

Fig. 5 Acrodus kalasinensis nov. sp. a Lateral tooth SM2012-1-006 in apical view. b, c Lateral tooth SM2012-1-007 in apical views. d, e Anterior tooth SM2012-1-008 in d apical and e lingual views. Scale bars represent $2 \mathrm{~mm}$ in $\mathbf{a}-\mathbf{c}$ and $1 \mathrm{~mm}$ in d, e 


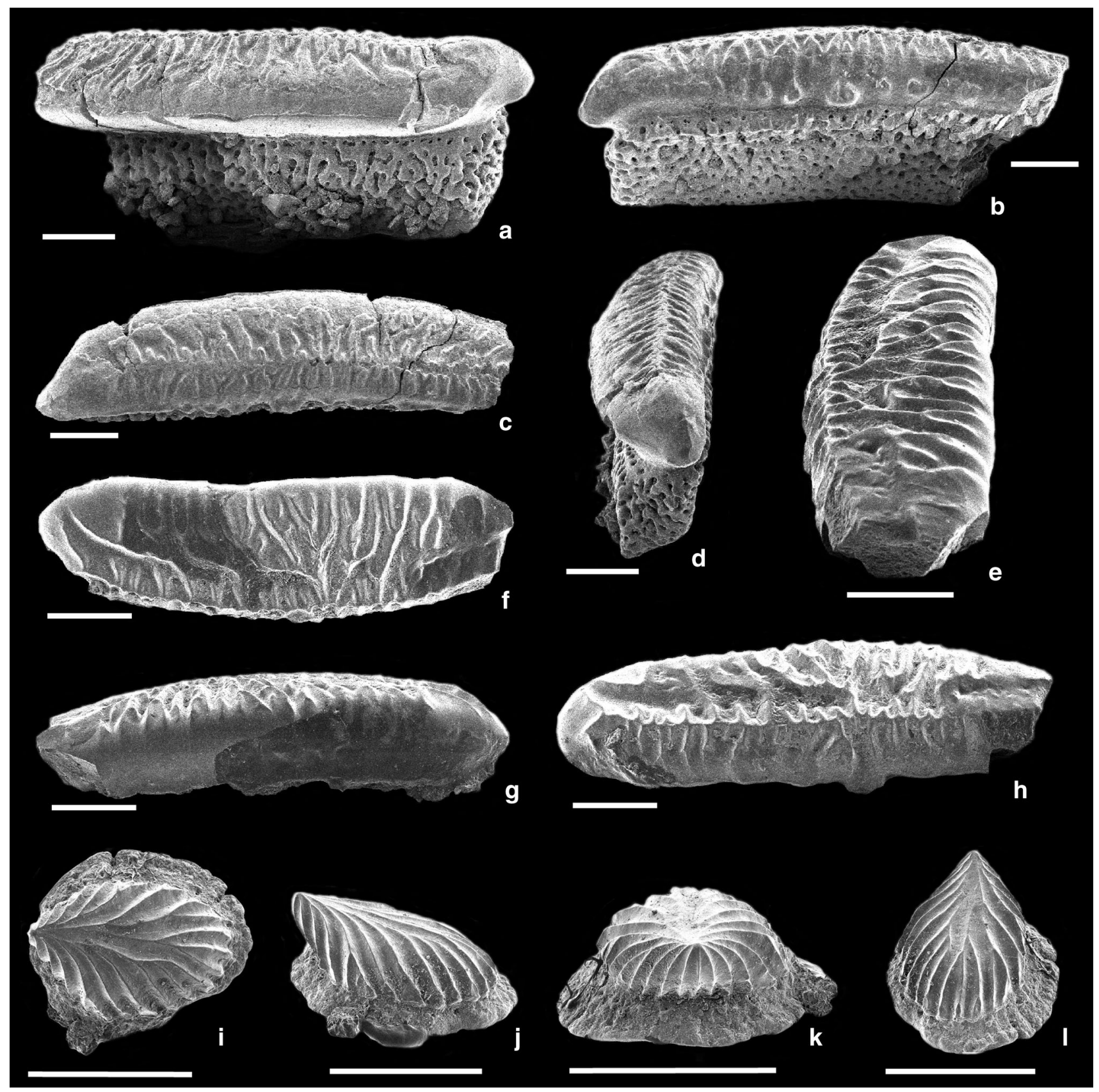

Fig. 6 a-h Acrodus kalasinensis nov. sp. a-d Holotype SM2012-1009 in a lingual, $\mathbf{b}$ labial, $\mathbf{c}$ apical and $\mathbf{d}$ mesio-apical or disto-apical views. e-h SM2012-1-010 in e mesio-apical or disto-apical, $\mathbf{f}$ apical,

largest teeth in the sample, two teeth belonging to the same tooth row still in connection (PRC63), attain $10 \mathrm{~mm}$ mesiodistally. The ornamentation of the crown of the holotype is very well developed, made of coarse, anastomosing ridges originating from the longitudinal crest. The latter is displaced labially. The ridges attain the base of the labial face, whereas the lingual one is smooth (Fig. 6a, g). The crown is flat, without cusp. The root is twice as high as the crown (Fig. 6a-c). It is quadrangular in shape with a flat base and $\mathbf{g}$ lingual and $\mathbf{h}$ labio-apical views. i-l Morphotype 1 dermal denticle SM2012-1-011 in $\mathbf{i}$ apical, $\mathbf{j}$ lateral, $\mathbf{k}$ caudal and $\mathbf{l}$ cranial views. All scale bars represent $1 \mathrm{~mm}$

is perforated by a multitude of randomly distributed small and large foramina. The root is projected lingually to varying degrees, making a maximum angle with the crown of $30^{\circ}$. The lingual face of the crown overhangs the root, and there is a row of small, aligned foramina just below the overhang.

On most teeth, the longitudinal crest is situated on the labial third of the apical surface, but in two teeth (SM20121-006 and SM2012-1-010), the latter attains the labial edge 
of the apical surface (Fig. 6e, f). On some teeth, such as PRC63 and the teeth from Chong Chat, the ornamentation ridges lingual to the longitudinal crest anastomose to each other, forming an irregular secondary longitudinal crest. One of these double-crested teeth (SM2012-1-008) shows a low cusp (Fig. 5d, e). At the level of this cusp, the crown is broader labio-lingually and tapers mesially and distally. The other teeth are more linear and quadrangular in outline. Their mesio-distal elongation varies from 3 to 26 times their labio-lingual width.

Comparison The teeth from Phu Noi share with those of Khoratodus foreyi from the Aptian/Albian Khok Kruat Formation of Thailand a low and flat profile with a shape elongated mesio-distally and narrow labio-lingually (Cuny et al. 2008). However, in the latter, the longitudinal crest is displaced lingually and not labially, and the ridges never attain the base of the labial face. In addition, the root is not as porous as in the specimens from Phu Noi, and shows a basal row of enlarged foramina (Cuny et al. 2008). One of the tooth fragments from Chong Chat was previously erroneously attributed to Heteroptychodus sp. by Cuny et al. (2007) based on the fact it shows two longitudinal crests. Its ornamentation is, however, coarser than in the latter genus.

The teeth from Phu Noi appear similar to those of Acrodus. According to Rees (2008), the Acrodontinae includes the genera Acrodus and possibly Asteracanthus, Palaeobates and Tribodus. Rees (2008) defined the Acrodontinae as possessing a crushing dentition with enlarged lateral teeth, and a complex ornamentation of the crown, but Tribodus does not possess the last two characters. The same author cites the following diagnostic characters for Acrodus: possession of cusp in anterior teeth, symmetrical enlarged lateral teeth and a porous root. This latter character is actually shared with Tribodus and the teeth from Phu Noi. The cusped SM2012-1-008 is likely to be an anterior or anterolateral tooth.

Two teeth from the Phu Kradung Formation were previously attributed to Acrodus by Cuny et al. (2003). One of these teeth, PRC81 (ex SHM-WD 219) from Wang Din So, is quite similar to SM2012-1-009 and SM2012-1-006, although in the former the ornamentation does not reach the base of the labial face. This perhaps corresponds to intraspecific variation, although this is difficult to test as only a few teeth are known from this site (Srisuk 2002). The second tooth, from Chong Chat, is double-crested (Fig. 3e in Cuny et al. 2003) and similar to the teeth from Phu Noi and Kham Phok. The presence of a double longitudinal crest in some teeth is reminiscent of the Triassic Acrodus spitzbergensis, but in the latter species, this character is absent from anterior teeth (Stensiö 1921; Rieppel et al. 1996; Cuny et al. 2001). The teeth from the Phu Kradung Formation share with those of $A$. undulatus from the Sinemurian of Belgium a longitudinal crest set on the labial part of the crown (Casier 1959). The same feature can be observed on the lateral teeth of A. caledonicus from the Bathonian of Scotland (Rees and Underwood 2006). The presence in the teeth from the Phu Kradung Formation of the following characters allows us to refer these teeth to Acrodus: cusped anterior teeth, crown with a complex ornamentation and a labially displaced longitudinal crest, and a porous root. They differ from those of A. biscrasseplicatus from the Middle Jurassic of Gansu (Northern China), the ornamentation of which is made of a few, short ridges (Xue 1980; Klug et al. 2010). The Thai material is therefore attributed to a new species, mainly based on the narrow aspect of the teeth-quite unusual in Acrodus.

The post-Toarcian A. caledonicus, A. biscrasseplicatus and $A$. kalasinensis n. sp. have all been recovered from freshwater environments (Rees and Underwood 2006; Klug et al. 2010), supporting Rees and Underwood's theory that this genus shifted from a marine to a non-marine environment during the Jurassic (Rees and Underwood 2006). This shift seems to be correlated with a reduction in size, as the post-Toarcian teeth do not exceed $15 \mathrm{~mm}$ mesio-distally (Xue 1980; Rees and Underwood 2006), whereas Early Jurassic teeth twice that size are not rare (Casier 1959). In addition, A. kalasinensis n. sp. may represent the youngest record of the genus (Rees 2000; Rees and Underwood 2006).

Family? Hybodontidae Owen, 1846

Dermal denticles

Figures 6i-1, 7a, b, 9e-h

Material PNA: 29 dermal denticles of morphotype 1 including SM2012-1-011, two of which are fused by their base. One dermal denticle of morphotype 2, SM2012-1012. PNB: 38 dermal denticles of morphotype 1, two pairs of which are fused by their base, including SM2012-1-022. PNC: two dermal denticles of morphotype 1.

Description These dermal denticles can be separated into two morphotypes: 1 and 2. Morphotype 1 is the most abundant, with more than 60 dermal denticles retrieved so far, whereas morphotype 2 is represented by a single specimen.

Morphotype 1 attains a maximum diameter of $2.5 \mathrm{~mm}$ and a height of $1.5 \mathrm{~mm}$. The crown is quite flat, with a triangular outline in apical view. Its apex projects beyond the base in most denticles. It is ornamented by numerous radiating ridges originating from its apex and often bifurcating in the lower half of the crown. They attain the base of the crown (Fig. 6i-1). The shape of the base in apical view is quite variable, from nearly circular to triangular, but it is always larger in diameter than the base of the 


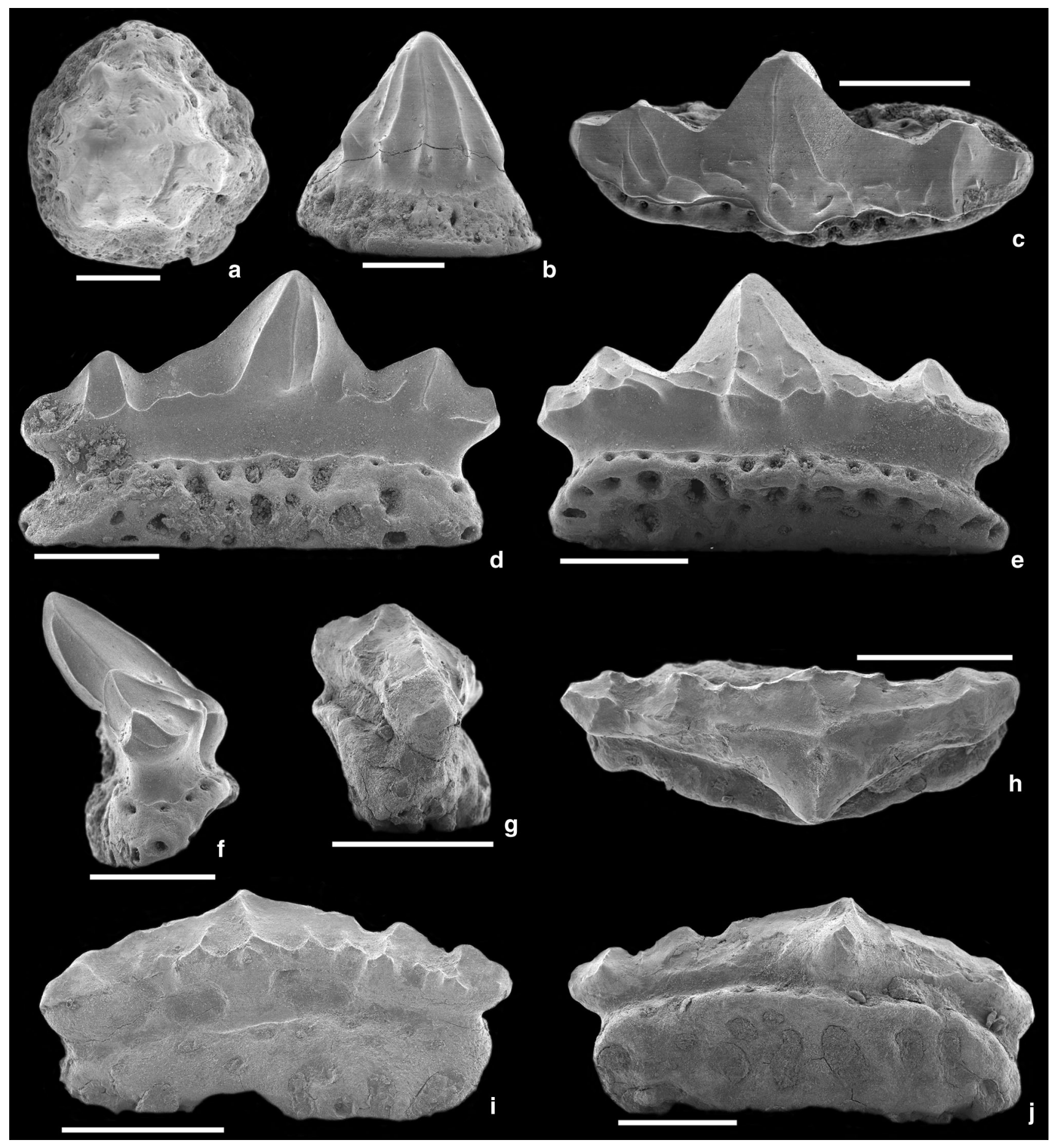

Fig. 7 a, b Morphotype 2 dermal denticle SM2012-1-012 in a apical and $\mathbf{b}$ lateral views. $\mathbf{c}-\mathbf{j}$ Jiaodontus sp. $\mathbf{c}-\mathbf{f}$ Anterior tooth SM2012-1013 in $\mathbf{c}$ apical, d lingual, e labial and $\mathbf{f}$ mesial or distal views.

crown. The basal face is convex and scattered with large foramina. Small foramina are also present around the crown on the upper surface, at the neck between crown and base. Two denticles can be fused at their bases, and three examples of such a phenomenon have been recorded (Fig. 9e-h). $\mathbf{g}-\mathbf{j}$ Posterior tooth SM2012-1-014 in $\mathbf{g}$ distal, $\mathbf{h}$ apical, $\mathbf{i}$ lingual and j labial views. All scale bars represent $500 \mu \mathrm{m}$

In morphotype 2, the crown is conical, upright and ornamented with 11 coarse, non-anastomosing ridges. The dermal denticle is $1.3 \mathrm{~mm}$ high and shows a maximum diameter at the base of $1.4 \mathrm{~mm}$. The base is almost circular in outline in basal view, larger in diameter than the crown (Fig. 7a, b). Its basal face is slightly concave and shows 
two foramina: one central, and one close to the external border. Small foramina are also irregularly distributed at the neck between crown and base.

Comparison The dermal denticles of morphotype 1 from Phu Noi are very similar to those found in the Khlong Min Formation in southern Thailand. They share a triangular crown with a similar pattern of ornamentation and a convex basal face devoid of a central foramen (Cuny et al. 2009). So far, this kind of dermal denticle is restricted to three localities in Thailand: Mab Ching, Ao Min (Khlong Min Formation, Nakhon Si Tammarat Province, BathonianCallovian) and Phu Noi. In Mab Ching, these denticles are associated with teeth of Hybodus only, whereas they are associated with teeth of Hybodus, Asteracanthus, Lonchidion and Belemnobatis at Ao Min (Cuny et al. 2009). Phu Noi has so far yielded teeth of Hybodus, aff. Hybodus, Acrodus, Jiaodontus, and Lonchidion (see below). As Hybodus is the only tooth type always found in association with the dermal denticles, it is possible that the two kinds of fossils belong to the same taxon. However, the Hybodus teeth from the Phu Kradung and the Khlong Min formations show differences in their ornamentation pattern (see above), and similar denticles would have been shared by different species. Moreover, dermal denticles of morphotype 1 are currently restricted to Phu Noi in the Phu Kradung Formation, whereas teeth of Hybodus sp. have been found at six sites (Phu Noi, Phu Nam Jun, Kham Phok, Chong Chat, Wang Din So and NBL32). Taking into account the sampling effort made at Chong Chat, the absence of these dermal denticles from this site is unlikely to be the result of a sampling bias. The association between Hybodus and the dermal denticles of type 1 must therefore be considered with caution.

The morphotype 2 denticle corresponds to a morphology not yet encountered in Southern Thailand. It is closer to morphotype $1 \mathrm{~b}$ described from the Oxfordian of Northwest China by Klug et al. (2010). However, taking into account the diversity of dermal denticle morphology that can be encountered in a single hybodont, as in for example $H y b$ odus delabechei (Reif 1978), it is difficult to say whether this morphotype 2 belonged to a different genus than the other denticles from Phu Noi.

Family Lonchidiidae Herman, 1977

Genus Jiaodontus Klug et al., 2010

Jiaodontus sp.

Figure $7 \mathrm{c}-\mathrm{j}$

Material PNA: One complete anterior tooth, SM2012-1013 , and 8 more or less fragmentary anterior and lateral teeth. Sang Khae: One complete posterior tooth, SM20121-014.
Description SM2012-1-013 measures $1.8 \mathrm{~mm}$ mesio-distally, $0.5 \mathrm{~mm}$ labio-lingually, and is $1.1 \mathrm{~mm}$ high, whereas SM2012-1-014 measures $1.4 \mathrm{~mm}$ mesio-distally, $0.5 \mathrm{~mm}$ labio-lingually, and is $0.7 \mathrm{~mm}$ high. SM2012-1-013 is slightly asymmetrical, with a well-developed triangular main cusp flanked by two pairs of lateral cusplets. The first ones are triangular in outline in labial or lingual view, whereas the second pair is incipient (Fig. 7c-f). SM20121-014 is more asymmetric, with an incipient main cusp flanked by three pairs of incipient cusplets (Fig. $7 \mathrm{~g}-\mathrm{j}$ ). The labial peg at the base of the main cusp is rounded and generally not well demarcated in the anterior and lateral teeth, whereas it is more demarcated and triangular in outline on the posterior tooth. A single crown fragment from Phu Noi shows a well-developed labial peg at the base of the main cusp, with a rather rectangular outline in apical view and almost perpendicular lateral edges. The longitudinal crest is well developed and uninterrupted between cusp and cusplets. Two to three rather irregular ridges ascend cusp and cusplets when the latter are well developed, and reach their apex. There are irregular, short ridges on the lower part of the crown that coalesce to form an irregular rim around the crown. Below this rim, the shoulder of the crown is smooth. There is a neat constriction between crown and root at the mesial and distal extremities of the teeth. The root is shallower than the crown and projects lingually. The labial shelf is very shallow, with a single row of small foramina, whereas foramina of various sizes are scattered on the basal and lingual faces. The baso-labial face is concave.

Comparison The presence of a labial peg not supported by a labial root buttress, a smooth crown shoulder surmounted by an irregular rim and the reduced labial root shelf with a single row of small foramina allow these teeth to be identified as belonging to Jiaodontus (Klug et al. 2010). They are quite similar to the teeth of J. montaltissimus but differ from the latter by a less developed and more rounded labial peg in anterior teeth, whereas the posterior tooth possesses a broader, more triangular one. They differ from the teeth of J. venedemus in possessing more demarcated cusp and cusplets in anterior teeth, and lacking a prominent vertical ridge on the lingual cusp face (Klug et al. 2010). As the posterior tooth comes from a different site than the anterior and lateral ones, it is deemed unwise to erect a new name, as we may have two different species in the Phu Kradung Formation. So far, Jiaodontus is restricted to the Oxfordian of northwestern China.

Genus Lonchidion Estes, 1964

Lonchidion sp. A

Figure 8a-h 


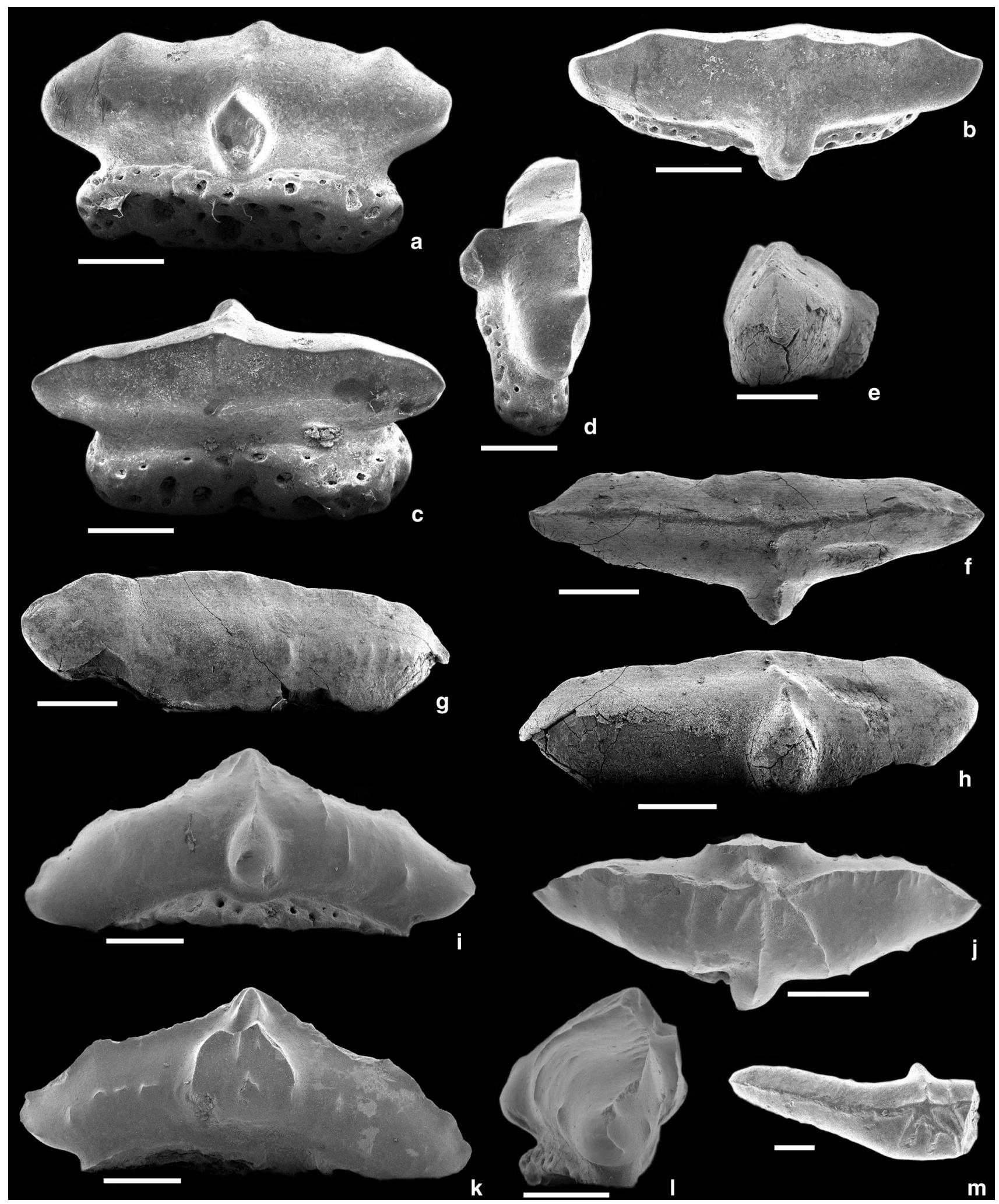

Fig. 8 a-h Lonchidion sp. A. a-d SM2012-1-015 in a labial, b apical, c apico-lingual and d apico-mesial or apico-distal views. e-h SM2012-1-016 in e mesial or distal, f apical, g lingual and

h labial views. $\mathbf{i}-\mathbf{m}$ Lonchidion sp. B. i-l SM2012-1-017 in i labial, $\mathbf{j}$ apical, $\mathbf{k}$ lingual and $\mathbf{I}$ mesial or distal views. $\mathbf{m}$ SM2012-1-018 in apical view. All scale bars represent $500 \mu \mathrm{m}$ 
Material PNA: SM2012-1-015-6 and ten unnumbered more or less complete crowns. Khok Sanam: One incomplete crown. NBL32: One crown.

Description The largest crown measures $3 \mathrm{~mm}$ mesio-distally, $1 \mathrm{~mm}$ labio-lingually at the level of the labial peg and is $1 \mathrm{~mm}$ high. Anterior teeth show a very low main cusp flanked by a pair of lateral incipient cusplets. The latter have a tendency to be absent on the lateral teeth, which are more elongated mesio-distally. A well-developed longitudinal crest crosses the whole crown, running through the apices of all cusp and cusplets (Fig. 8c-f). In addition to this crest, there are sometimes some faint ridges on the lingual part of the crown, but most of the teeth are smooth. The labial peg, at the base of the crown, is well developed and narrow with almost parallel mesial and distal faces in anterior teeth. It becomes more triangular in outline in more posterior teeth. The base of the crown is neatly constricted mesio-distally, so that the root insertion area is shorter than the upper part of the crown (Fig. 8a, c, g, h). Its base is also constricted labio-lingually, but much less than mesio-distally.

A single tooth, SM2012-1-015, has the root preserved (Fig. 8a-d). It is half the height of the crown and is shorter mesio-distally than the latter. It is, however, more expanded than the base of the crown both lingually and labially. Large foramina open randomly on all faces of the root, the largest being on the basal face.

Comparison The presence of a well-developed, narrow labial peg together with a root wider than the lowermost part of the crown allow us to refer the teeth described above to Lonchidion (Rees and Underwood 2002). The lack of ornamentation of the crown is reminiscent of Lonchidion noncostatus from the Kimmeridgian of Germany, $L$. breve from the Early Cretaceous of Britain, and $L$. microselachos from the Early Cretaceous of Spain (Duffin 2001). L. noncostatus and L. microselachos may be separated from the teeth of $L$. sp. A in possessing a ridge or an accessory cusplet on the labial peg, whereas $L$. breve is devoid of lateral cusplet.

So far, Lonchidion has been mentioned from three localities in Thailand: Wang Din So, Phu Phan Thong (Sao Khua Formation, Nong Bua Lamphu Province) and Ao Min (Khlong Min Formation, Nakhon Si Tammarat Province) (Cuny et al. 2007). Teeth of $L$. reesunderwoodi from Ao Min can easily be separated from the teeth from the Phu Kradung Formation by their ornamented crown and the presence of a lingual protuberance at the base of the main cusp (Cuny et al. 2009). Teeth of L. khoratensis from Phu Phan Thong differ from the teeth of $L$. sp. A in lacking a cusp and possessing a sharp longitudinal crest (Cuny et al. 2006). The teeth from Wang Din So, first described by Srisuk (2002) as Lissodus sp. (but see below), show an ornamented crown, contrary to the teeth of $L$. sp. A.

\section{Lonchidion sp. B}

Figure 8i-m

Material PNA: Five incomplete crowns, including SM2012-1-018. PNB: Mesial and distal extremity of a tooth with the root preserved, but the central part of the crown is missing. Kham Phok: One complete, SM2012-1017, and 13 fragmentary crowns. NBL32: Two fragmentary crowns. Wang Din So: 17 crowns, including PRC83 and PRC84.

Description SM2012-1-017 measures $2.8 \mathrm{~mm}$ mesio-distally, $1.1 \mathrm{~mm}$ labio-lingually, and is $1.2 \mathrm{~mm}$ high. The crown shows a low main cusp and a pair of incipient lateral cusplets, which have a tendency to disappear on the mesiodistally elongated lateral teeth. In apical view, the mesial and distal extremities of the crown taper, so that their ends are pointed. These teeth show a well-developed longitudinal crest from which short ridges originate that never attain the base of the crown. These ridges are longer on the main cusp than on the rest of the crown. The labial peg is quite small, narrow, and restricted to the lower half of the crown. It bears a median ridge. On more distal teeth, the labial peg becomes more triangular and less demarcated from the main cusp. The lingual peg is not as developed as the labial one, but it is broader. It bears at least a median ridge. The latter often bifurcates basally, forming an inverted Y. There are short ridges at the base of the labial and lingual faces, which may form small nodes (Fig. 8i-1).

Only the tooth fragments recovered from PNB have the root well preserved. There is a neat constriction separating it from the crown, and it is shorter mesio-distally than the crown. The root is as high as the crown, and it slightly projects lingually. There is a shelf on the upper labial face bearing a single row of circular foramina. The row is quite regular at one end, but much less at the other end. Below it, the lower part of the labial face is concave and scattered with small foramina. The lingual face is slightly convex in mesial or distal view and scattered with foramina larger than the labial ones. SM2012-1-017 has a fragment of root preserved, which also shows a single row of foramina on the upper part of the labial face.

SM2012-1-018 is unusual in that the mesial and distal extremities of the teeth are arched labially, so that the labial peg seems to be in a lingual position. Its morphology is, however, similar to that of the labial peg of the other teeth. It could represent a pathological tooth.

Comparison The absence of a basal rim near the base of the crown in the teeth described above allows us to differentiate them from those of Jaiodontus (Klug et al. 2010). Based on the ornamentation of their crown, the teeth from Kham Phok and Wang Din So were attributed to Lissodus (Srisuk 2002; Cuny et al. 2007). However, their gracile aspect and the fact that they are narrow labio-lingually with 
pointed mesial and distal extremities suggest they belong instead to Lonchidion (Rees and Underwood 2002). These teeth differ from those of Lonchidion sp. A by a more ornamented crown and a labial peg less prominent than in the latter.

The teeth of $L$. sp. B are quite similar to those of $L$. reesunderwoodi, but separate from them by the absence of a second pair of lateral cusplets and a less prominent labial peg (Cuny et al. 2009). The teeth of $L$. inflexum from the Lower Cretaceous of England possess a better developed labial peg and a more angled crown in apical view than those of $L$. sp. B (Underwood and Rees 2002). The teeth of L. crenulatum, also from the Lower Cretaceous of England, as well as those of $L$. anitae from the ?Aptian-Albian of Texas differ from those of $L$. sp. B in possessing cusplets and a labial peg that are better developed, as well as lacking small foramina on the labial face of the root just under the crown (Duffin 2001; Underwood and Rees 2002). Teeth of $L$. striatum possess a denser ornamentation and are devoid of a lingual peg (Duffin 2001).

Family incertae sedis

Genus Heteroptychodus Yabe and Obata, 1930

Heteroptychodus cf. H. kokutensis Cuny et al., 2010

Figure $9 \mathrm{a}-\mathrm{d}$
Material Kham Phok: One almost complete tooth, SM2012-1-019, and 19 more or less fragmentary crowns. Sang Khae: One fragmentary crown.

Description The largest tooth, SM2012-1-019, measures $4.5 \mathrm{~mm}$ mesio-distally (with the mesial or distal extremity missing), $1.5 \mathrm{~mm}$ labio-lingually, and is $2 \mathrm{~mm}$ high, including the root. The crowns are elongated mesio-distally, flat or slightly convex, without cusp, and ornamented by a set of crests running mesio-distally and parallel to each other. There are two to four crests. Only the most labial one reaches the mesial and distal extremities of the crown. Lingually, they become shorter. Small, short ridges originate both lingually and labially from the most labial crest and are perpendicular to the latter. In more lingual crests, short ridges run on their lingual side only (Fig. 9a). The lingual part of the apical face of the crown is ornamented by coarse, irregular and anastomosing ridges, which sometimes form nodes on the upper part of the lingual face. The latter is otherwise smooth and slopes labially, so that the apical surface is larger than the basal one (Fig. 9b). The labial face is convex in mesial or distal view and shows in its basal part short ridges that do not, however, reach the base of the crown. They sometimes form nodes, for example in SM2012-1-019 and the crown from Sang Khae (Fig. 9c, d).
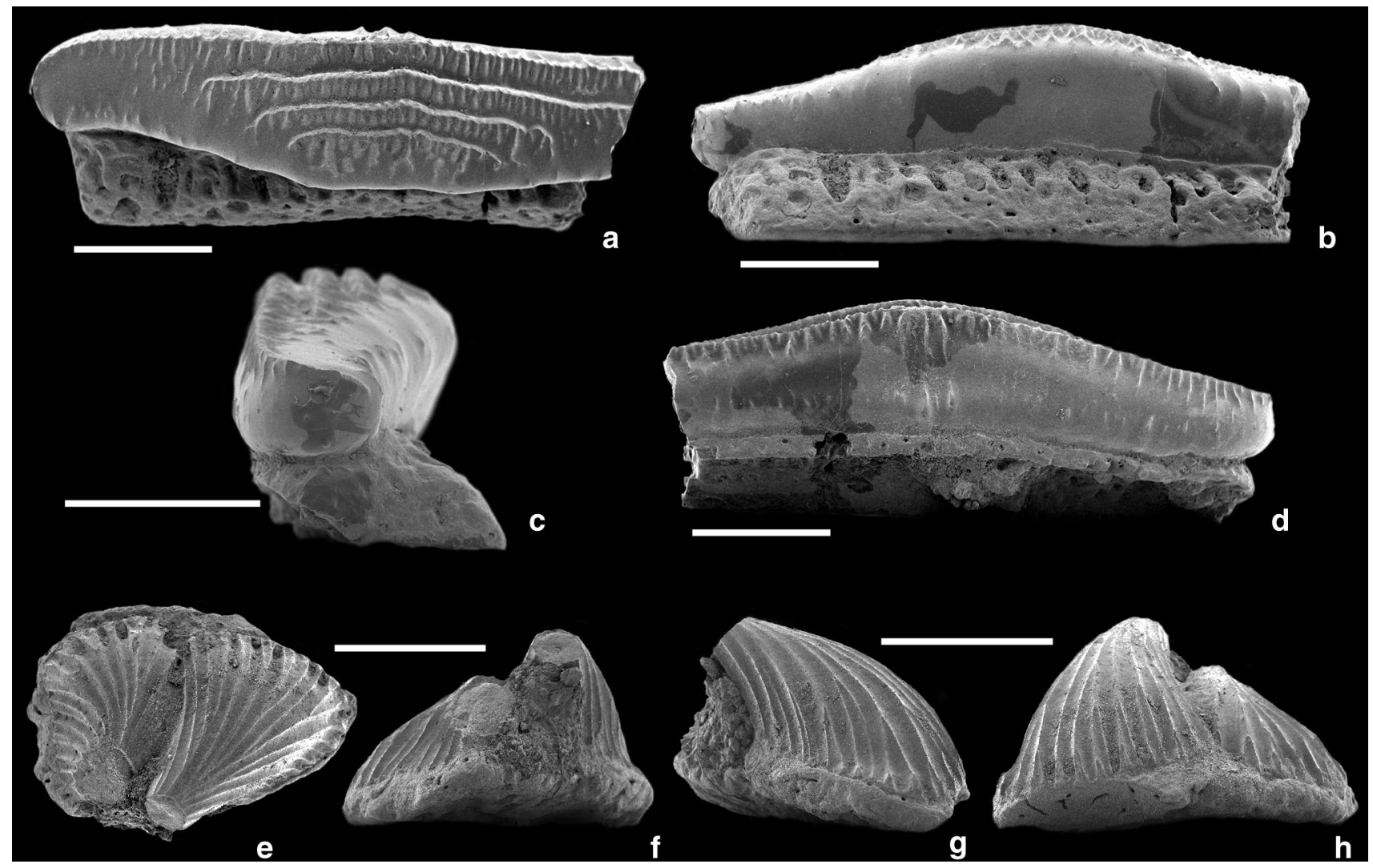

Fig. 9 a-d Heteroptychodus cf. H. kokutensis SM2012-1-019 in a apical, b lingual, c mesial or distal and d labial views. e-h Dermal denticles of morphotype 1 fused at their bases, SM2012-1-022, in e apical, f posterior, $\mathbf{g}$ lateral and $\mathbf{h}$ anterior views. All scale bars represent $1 \mathrm{~mm}$ 
SM2012-1-019 is the only tooth with the root preserved. A well-defined groove separates it from the crown on both the labial and lingual faces. The root is approximately as high as the crown and is projected lingually. On the labial face, there is a well-developed shelf just under the crown showing a row of small foramina. Below the shelf, the root is concave with irregularly distributed foramina and slopes lingually. The lingual face shows large, irregular foramina in the upper half and smaller foramina in the lower half. The basal face is flat.

Comparison A posterior tooth of Heteroptychodus steinmanni (SM2012-1-020, ex-TF7675) from Phu Phan Thong (Nong Bua Lamphu Province, Sao Khua Formation) is reminiscent of the teeth described here as it shows mesio-distal ridges decreasing in size lingually (Cuny et al. 2006, Fig. 4a-e). However, a number of characters separate SM2012-1-020 from the teeth of the Phu Kradung Formation: the presence of more numerous mesio-distal crests, the smooth labial surface of the crown and a root which is not projected lingually. The latter teeth cannot therefore be attributed to the species $H$. steinmanni.
However, the similar pattern of ornamentation, as well as the small size of the teeth, suggest that these teeth are likely to be posterior teeth. Their ornamented labial face is reminiscent of $H$. kokutensis (Cuny et al. 2010), but the posterior teeth of this species, as well as those of $\mathrm{H}$. chuvalovi, are so far unknown, making comparisons difficult.

The root of Heteroptychodus cf. H. kokutensis is very similar to that of Jaiodontus, as they share a very shallow labial shelf with a single row of circular foramina.

Dorsal finspines

Figure 10

Material PNB: One almost complete spine (SM2012-1001) and 11 more or less fragmentary spines. Khok Sanam: Several fragments. Wang Din So: Four spines, including PRC79 and PRC80. Kham Phok: Two spine fragments.

Description SM2012-1-001 is $80 \mathrm{~mm}$ long and shows seven enamelled costae on each side at its base, and four near the apex (Fig. 10a, c). New costae intercalate in between the apical ones in the upper quarter of the spine
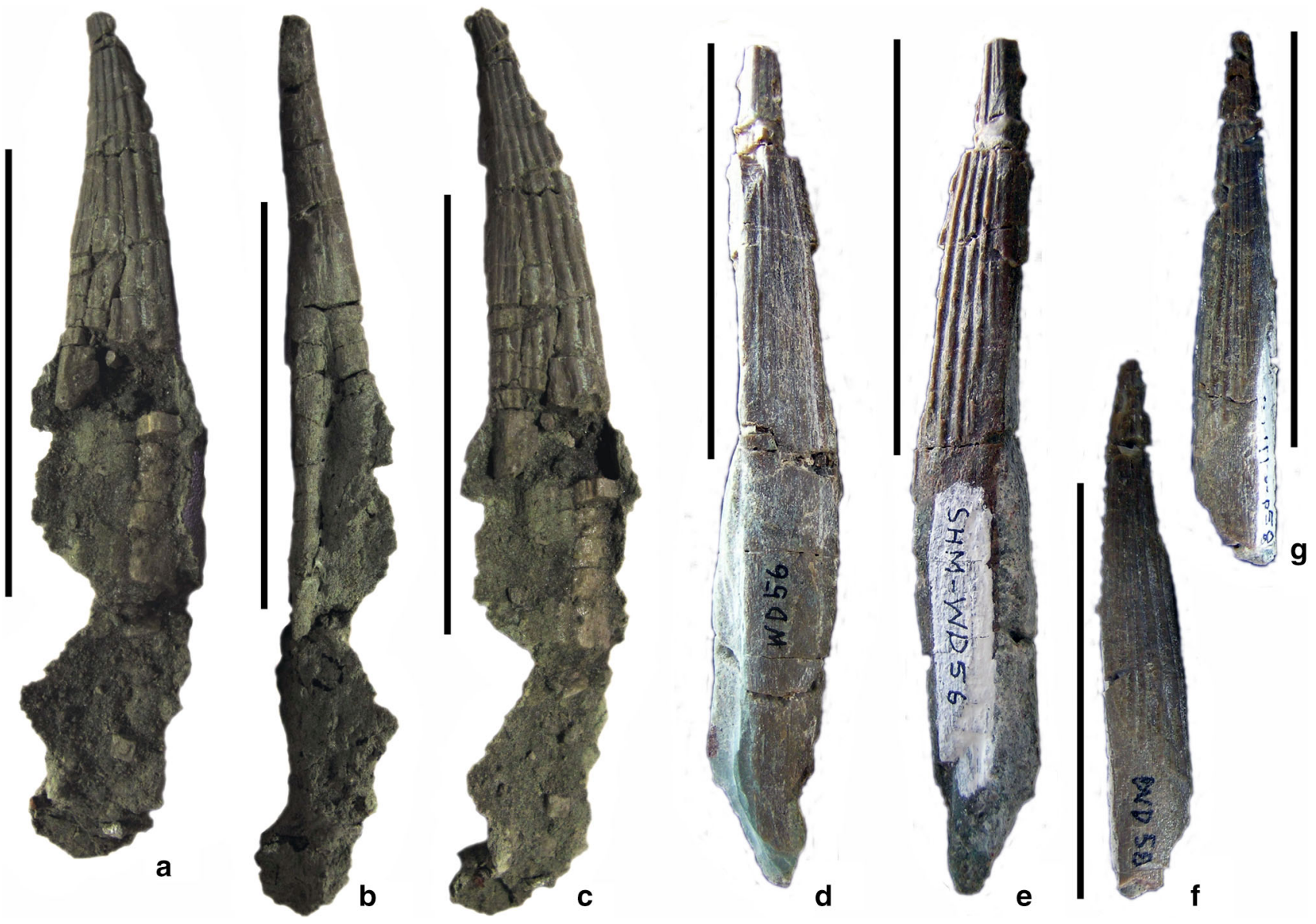

Fig. 10 Hybodont dorsal finspines. a-c SM2012-1-001 in a, c lateral and b caudal views. d, e PRC79 in lateral views. f, $\mathbf{g}$ PRC80 in lateral views. All scale bars represent $50 \mathrm{~mm}$ 
(Fig. 10c). The largest finspine recovered so far is PRC79 from Wang Din So (Fig. 10d, e). It is $102 \mathrm{~mm}$ long and seems to have only five costae on each side, although its state of preservation makes counting quite difficult. More fragmentary remains show up to eight costae on each side, and a minimum of three at the distal extremity. There is an enamelled keel on the anterior wall. The posterior wall is nearly flat, giving the spines an almost triangular section. On their upper half, there is a row of alternating denticles. In SM2012-1-001, each posterior denticle has a roughly triangular outline in lateral view. A $17 \mathrm{~mm}$ long, fragmentary spine from Kham Phok shows ten denticles on the posterior wall. The top six are disposed along an alternated line, whereas the four lower ones form two parallel rows. This spine appears to be curved anteriorly, and could be pathological. The lower half of the posterior wall of the spines is open (Fig. 10b). One fragmentary spine from Phu Noi is broken in the middle and shows that the central cavity is situated in the middle of the spine.

Comparison The finspines from the Phu Kradung Formation appear quite similar to the ones found in the Sao Khua Formation (Cuny et al. 2007). They are, however, quite different from the ones found in the Khlong Min Formation, which show an ornamentation mostly made of tubercles, with costae being present only at the apex of the spines (Cuny et al. 2005).

SM2012-1-001, PRC79 and PRC80 are probably too large to match the minute teeth of Jaiodontus or Lonchidion. They are therefore more likely to belong to Hybodus or Acrodus, but these two genera may possess identical finspines (Maisey 1978). The more fragmentary spines from Khok Sanam and Kham Phok are also found in association with more than one taxon based on teeth (Fig. 1). It is therefore not possible to reach any precise identification for this material.

\section{Discussion}

Stratigraphic implications

Both Hybodus and Lonchidion have a vast stratigraphic range, from at least the Triassic to the Late Cretaceous (Cappetta 2012), so they are not helpful when attempting to date the Phu Kradung Formation. Outside of Thailand and the Phu Kradung Formation, the oldest record of Heteroptychodus is from the Lower Cretaceous Matsuo Group of Japan (Tanimoto and Tanaka 1998). On the other hand, the genus Acrodus is restricted to the Triassic and the Jurassic (Rees and Underwood 2006), and the morphotype I dermal denticles from Phu Noi are only known from the Bathonian-Callovian Khlong Min Formation. It should be noted, however, that in many sites where teeth have been described, the dermal denticles have not, so that the range of their morphotypes is virtually unknown (Charlie Underwood, pers, comm., October 2012). In addition, so far, Jaiodontus is restricted to the Oxfordian of China (Klug et al. 2010). So, apart from Heteroptychodus, the shark fauna supports a Jurassic age for the Phu Kradung Formation rather than a Cretaceous one. However, the Jurassic components are known mainly from the lower part of the studied interval (Fig. 1). Only rare tooth fragments of Acrodus are known in the upper part at Kham Phok and Chong Chat, but Jaiodontus and Heteroptychodus are found together at Sang Khae. The stratigraphical ranges of "Jurassic" and "Cretaceous" genera therefore overlap. The rarity of Jurassic hybodonts in the upper part of the interval might indicate that the Jurassic/Cretaceous boundary is situated in the uppermost part of the Phu Kradung Formation, with Kham Phok, based on the abundance of Heteroptychodus, as the youngest of the eight sites studied. However, the discovery of a sinraptorid theropod dinosaur at Kham Phok (Buffetaut and Suteethorn 2007) would rather suggest a Jurassic age for this site. Conversely, palynological data suggest an Early Cretaceous age for most of the Phu Kradung Formation (Racey and Goodall 2009).

The detrital zircon thermochronology study conducted by Carter and Bristow (2003) suggested an Early Cretaceous age for the Phu Kradung Formation, but they also identified a Late Jurassic zircon source in their samples. The latter were collected near Phakdi Chumphon, in the western part of Chaiyaphum province, at least $300 \mathrm{~km}$ away from any of the sites that have yielded vertebrate microremains, in the more southern part of the Khorat Plateau. As a result, precise correlation with the eight sites included in the present work is not possible.

Palaeogeographic implications

From a palaeogeographic point of view, the data are equally difficult to decipher. Hybodus teeth from the Phu Kradung Formation are quite similar to those of the Chinese $H$. huangnidanensis and Hybodus sp. from Hubei province, but on the other hand this is a widespread morphology among this genus that can also be observed in Jurassic and Cretaceous European teeth (see for example Ansorge 1990, fig. 3; Kriwet et al. 1997, fig. 3a; Rees and Underwood 2006, fig. 4). The genus Acrodus is known in the Middle Jurassic of both China and Europe, but $A$. kalasinensis nov. sp. appears closer to the European $A$. caledonicus than to the Chinese A. biscrasseplicatus, the latter showing a reduced ornamentation of the crown, an uncommon condition among this genus. Lonchidion is so far unknown in China, and the teeth of Lonchidion sp. A from Phu Noi appear closer to those of European species 
than to any other species (see above). The presence of cf. Theriosuchus in the Phu Kradung Formation also supports a European affinity for some of its faunal components (Lauprasert et al. 2011).

On the other hand, Jaiodontus is a freshwater shark that is restricted to northwestern China so far. It is thus probably an immigrant from China. The bony fish faunas, as well as the turtle and dinosaur assemblages of the Phu Kradung Formation, also support faunal exchanges between China and Thailand during the Late Jurassic (Cavin et al. 2003a, 2009; Buffetaut and Suteethorn 2007; Tong et al. 2009a).

Heteroptychodus is currently restricted to Thailand, Japan, Kyrgystan, South China and Mongolia, and the tooth from Sang Khae is likely to represent its oldest record (Cuny et al. 2008). It is thus possible that this genus first appeared in Southeast Asia and expanded its distribution later on towards the North and the West in Japan, Kyrgystan, South China and Mongolia. As both Acrodus and Heteroptychodus possess grinding dentition, it is also possible that the latter replaced the former in its ecological niche. The two taxa occur together at Kham Phok, but Acrodus is very rare there, which suggests a replacement by competition, rather than an opportunistic one after the disappearance of Acrodus.

The dermal denticles of morphotype 1 from Phu Noi appear endemic to Thailand, and their absence so far in either China or Europe may indicate the evolution of an endemic set of Hybodus species in Thailand if these dermal denticles do indeed belong to this genus. Finally, the phylogenetic affinities of the teeth of aff. Hybodus are too badly understood to analyze their palaeogeographic relationships in a meaningful way.

The peculiar freshwater hybodont assemblage from the Phu Kradung Formation appears therefore to share both European (A. kalasinensis nov. sp., Lonchidion sp. A) and Asian (Jaiodontus, Heteroptychodus) affinities.

\section{Conclusions}

The discovery of Phu Noi has significantly increased our knowledge of the hybodont sharks from the Phu Kradung Formation, allowing the recognition of a new species, $A$. kalasinensis, which represents the youngest occurrence of the genus and confirms its displacement in freshwater environments after the Toarcian. Together with the presence of Jaiodontus and of the dermal denticles of morphotype 1, it suggests a Late Jurassic age for most of the Phu Kradung Formation, whereas the presence of Heteroptychodus suggests an Early Cretaceous age for the top of the Formation. As it is the oldest occurrence of the latter genus, it also suggests a Thai origin for Heteroptychodus, which may have replaced $A$. kalasinensis nov. sp. in the Thai freshwater palaeoecosystems. However, the age of the Phu Kradung Formation is still uncertain, with contradictory signals coming from palynology, detrital zircon thermochronology and vertebrate palaeontology.

The shark assemblages of the Phu Kradung Formation appear to share both European and Asian affinities. The peculiar dermal denticles of morphotype 1 appear so far to be restricted to Thailand, but their exact phylogenetic affinities remain difficult to decipher.

Acknowledgments The authors would like to thank Paladej Srisuk for making his collection available for study, and then donating it to the Palaeontological Research and Education Centre of Mahasarakham University. We also thank Ms. Nual-Anong Narkkong for her help with the SEM at Mahasarakham University. Stefanie Klug and Charlie Underwood's comments during the reviewing process greatly improved the quality of the manuscript. GC's work was funded by the Carlsberg Foundation, and was carried out under National Research Council of Thailand authorizations 126/51 and 102/54.

Open Access This article is distributed under the terms of the Creative Commons Attribution License which permits any use, distribution, and reproduction in any medium, provided the original author(s) and the source are credited.

\section{References}

Agassiz, L. 1833-44. Recherches sur les poissons fossiles. Neuchâtel and Soleure: imprimerie Petitpierre.

Ansorge, J. 1990. Fischreste (Selachii, Actinopterygii) aus der Wealdentonscholle von Lobber Ort (Mönchgut/Rügen/DDR). Paläontologische Zeitschrift 64: 133-144.

Boggs, J.S. 1987. Principles of sedimentology and stratigraphy. Columbus: Merrill Publishing Co.

Buffetaut, E., and V. Suteethorn. 2007. A sinraptorid theropod (Dinosauria: Saurischia) from the Phu Kradung Formation of northeastern Thailand. Bulletin de la Société Géologique de France 178(6): 497-502.

Buffetaut, E., V. Suteethorn, and H. Tong. 2001. The first thyreophoran dinosaur from Southeast Asia: a stegosaur vertebra from the Late Jurassic Phu Kradung Formation of Thailand. Neues Jahrburg für Geologie und Paläontologie, Monatshefte 2001: 95-102.

Cappetta, H. 2012. Handbook of Paleoichthyology: Chondrichthyes. Mesozoic and Cenozoic Elasmobranchii: Teeth. München: Verlag Dr. Friedrich Pfeil.

Carter, A., and C. Bristow. 2003. Linking hinterland evolution and continental basin sedimentation by using detrital zircon thermochronology: a study of the Khorat Plateau Basin, eastern Thailand. Basin Research 15: 271-285.

Casier, E. 1959. Contributions à l'étude des Poissons fossiles de la Belgique. XII. Sélaciens et Holocephales sinémuriens de la province de Luxembourg. Bulletin de l'Institut Royal des Sciences Naturelles de Belgique 35: 1-27.

Cavin, L., and V. Suteethorn. 2006. A new semionotiform (Actinopterygii, Neopterygii) from Upper Jurassic-Lower Cretaceous deposits of North-East Thailand, with comments on the relationships of Semionotiforms. Palaeontology 49(2): 339-353.

Cavin, L., V. Suteethorn, E. Buffetaut, K. Lauprasert, J. Le Loeuff, P. Lutat, M. Philippe, U. Richter, and H. Tong. 2003a. 
Palaeobiogeographical affinities of the fishes from Phu Nam Jun, Late Jurassic-Early Cretaceous of North-Eastern Thailand. Mahasarakham University Journal (special issue) 22: 217-227.

Cavin, L., V. Suteethorn, S. Khansubha, E. Buffetaut, and H. Tong. 2003b. A new semionotid (Actinopterygii, Neopterygii) from the Late Jurassic-Early Cretaceous of Thailand. Comptes Rendus Palevol 2: 291-297.

Cavin, L., V. Suteethorn, E. Buffetaut, and H. Tong. 2007. A new Thai Mesozoic lungfish (Sarcopterygii, Dipnoi) with an insight into post-Palaeozoic dipnoan evolution. Zoological Journal of the Linnean Society 149: 141-177.

Cavin, L., U. Deesri, and V. Suteethorn. 2009. The Jurassic and Cretaceous bony fish record (Actinopterygii, Dipnoi) from Thailand. In Late Palaeozoic and Mesozoic Ecosystems in SE Asia, vol 315, eds. E. Buffetaut, G. Cuny, J. Le Loeuff, and V. Suteethorn, 125-139. London: The Geological Society Special Publications.

Cuny, G., O. Rieppel, and P.M. Sander. 2001. The shark fauna from the Middle Triassic (Anisian) of North-Western Nevada. Zoological Journal of the Linnean Society 133: 285-301.

Cuny, G., V. Suteethorn, E. Buffetaut, and M. Philippe. 2003. Hybodont sharks from the Mesozoic Khorat Group of Thailand. Mahasarakham University Journal 22 special issue: 49-68.

Cuny, G., V. Suteethorn, and S. Kamha. 2005. A review of the hybodont sharks from the Mesozoic of Thailand, 588-593. In Proceedings of the International Conference on Geology, Geotechnology and Mineral Resources of Indochina (GEOINDO 2005), eds. L. Wannakao, W. Youngme, K. Srisuk, and R. Lertsirivorakul, 610-614. Khon Kaen: Khon Kaen University.

Cuny, G., V. Suteethorn, S. Kamha, E. Buffetaut, and M. Philippe. 2006. A new hybodont shark assemblage from the Lower Cretaceous of Thailand. Historical Biology 18(1): 21-31.

Cuny, G., V. Suteethorn, S. Khama, K. Lauprasert, P. Srisuk, and E. Buffetaut. 2007. The Mesozoic fossil record of sharks in Thailand. In Proceedings of the International Conference on Geology of Thailand: towards sustainable development and sufficiency economy, ed. W. Tantiwanit, 349-354. Bangkok: Department of Mineral Resources.

Cuny, G., V. Suteethorn, S. Kamha, and E. Buffetaut. 2008. Hybodont sharks from the Lower Cretaceous Khok Kruat Formation of Thailand, and hybodont diversity during the Early Cretaceous. In Fishes and the break-up of Pangaea, vol 295, eds. L. Cavin, A. Longbottom, and M. Richter, 93-107. London: Geological Society Special Publications.

Cuny, G., P. Srisuk, S. Khamha, V. Suteethorn, and H. Tong. 2009. A new elasmobranch fauna from the Middle Jurassic of southern Thailand. In Late Palaeozoic and Mesozoic Ecosystems in SE Asia, vol 315, eds. E. Buffetaut, G. Cuny, J. Le Loeuff, and V. Suteethorn, 97-113. London: Geological Society Special Publications.

Cuny, G., C. Laojumpon, O. Cheychiw, and K. Lauprasert. 2010. Fossil vertebrate remains from Kut Island (Gulf of Thailand, Early Cretaceous). Cretaceous Research 31: 415-423.

Department of Mineral Resources. 2001. Geology of Thailand. Bangkok: Ministry of Natural Resources and Environment. (in Thai).

Department of Mineral Resources. 2010. Geological Atlas of Thailand. Bangkok: Ministry of Natural Resources and Environment.

Duffin, C.J. 2001. Synopsis of the selachian genus Lissodus Brough, 1935. Neues Jahrbuch für Geologie und Paläontologie Abhandlungen 221: 145-218.

Estes, R. 1964. Fossil vertebrates from the late Cretaceous Lance Formation, Eastern Wyoming. University of California Publications in Geological Sciences 49: 1-180.
Hay, O.P. 1902. Bibliography and catalogue of the fossil vertebrate of North America. Bulletin of the United States Geological Survey 179: $1-868$

Herman, J. 1977. Les sélaciens des terrains néocrétacés and paléocènes de Belgique and des contrées limitrophes. Éléments d'une biostratigraphie intercontinentale. Mémoires pour servir à l'Explication des cartes Géologiques et Minières de la Belgique 15: $1-450$.

Huxley, T.H. 1880. On the application of the laws of evolution to the arrangement of the vertebrata, and more particularly of the Mammalia. Proceedings of the Zoological Society 1880: 649-662.

Klug, S., T. Tütken, O. Wings, H.-U. Pfretzschner, and T. Martin. 2010. A Late Jurassic freshwater shark assemblage (Chondrichthyes, Hybodontiformes) from the southern Junggar Basin, Xinjiang, Northwest China. Palaeobiodiversity and Palaeoenvironments 90: 241-257.

Kriwet, J., O.W.M. Rauhut, and U. Gloy. 1997. Microvertebrate remains (Pisces, Archosauria) from the Middle Jurassic (Bathonian) of southern France. Neues Jahrburg für Geologie und Paläontologie Abhandlungen 206: 1-28.

Lauprasert, K., C. Laojumpon, W. Saenphala, G. Cuny, K. Thirakhupt, and V. Suteethorn. 2011. Atoposaurid crocodyliforms from the Khorat Group of Thailand: first record of Theriosuchus from Southeast Asia. Paläontologische Zeitschrift 85: 37-47.

Liard, R., and J.E. Martin. 2011. Relative position of the Mesozoic vertebrate localities in the Phu Kradung Formation of the Phu Phan uplift, Northeast Thailand. In World Conference on Paleontology and Stratigraphy program and abstract, 191-192, Nakhon Ratchasima: Northeastern Research Institute of Petrified Wood and Mineral Resources (NRIP).

Maisey, J.G. 1978. Growth and form of finspines in hybodont sharks. Palaeontology 21: 657-666.

Maisey, J.G. 1987. Cranial anatomy of the Lower Jurassic shark Hybodus reticulatus (Chondrichthyes: Elasmobranchii), with comments on hybodontid systematics. American Museum Novitates 2878: 1-39.

Maisey, J.G. 1989. Hamiltonichthys mapesi, g. and sp. nov. (Chondrichthyes; Elasmobranchii), from the Upper Pennsylvanian of Kansas. American Museum Novitates 2931: 1-42.

Mouret, C. 1994. Geological history of northeastern Thailand since the Carboniferous. Relations with Indochina and Carboniferous to Early Cenozoic evolution model. In Proceedings of the International Symposium on Stratigraphic Correlation of Southeast Asia, ed. P. Angsuwathana, 132-158. Bangkok: Department of Mineral Resources and IGCP.

Owen, R. 1846. Lectures on the comparative anatomy and physiology of the vertebrate animals, delivered at the Royal College of Surgeons of England in 1844 and 1846. Part 1. Fishes. London.

Patterson, C. 1966. British Wealden sharks. Bulletin of the British Museum (Natural History) Geology 11: 283-350.

Philippe, M., V. Suteethorn, P. Lutat, E. Buffetaut, L. Cavin, G. Cuny, and G. Barale. 2004. Stratigraphical and palaeobiogeographical significance of fossil wood from the Mesozoic Khorat Group of Thailand. Geological Magazine 141(3): 319-328.

Philippe, M., V. Daviero-Gomez, and V. Suteethorn. 2009. Silhouette and palaeoecology of Mesozoic trees in Thailand. In Late Palaeozoic and Mesozoic Ecosystems in SE Asia, vol 315, eds. E. Buffetaut, G. Cuny, J. Le Loeuff, and V. Suteethorn, 85-96. London: Geological Society Special Publications.

Racey, A. 2009. Mesozoic red bed sequences from SE Asia and the significance of the Khorat Group of NE Thailand. In Late Palaeozoic and Mesozoic Ecosystems in SE Asia, vol 315, eds. E. Buffetaut, G. Cuny, J. Le Loeuff, and V. Suteethorn, 41-67. London: Geological Society Special Publications. 
Racey, A., and J.G.S. Goodall. 2009. Palynology and stratigraphy of the Mesozoic Khorat Group red bed sequences from Thailand. In Late Palaeozoic and Mesozoic Ecosystems in SE Asia, vol 315, eds. E. Buffetaut, G. Cuny, J. Le Loeuff, and V. Suteethorn, 69-83. London: Geological Society Special Publications.

Racey, A., M.A. Love, A.C. Canham, J.G.S. Goodall, S. Polachan, and P.D. Jones. 1996. Stratigraphy and reservoir potential of the Mesoizoic Khorat Group, NE Thailand. Part 1: Stratigraphy and sedimentary evolution. Journal of Petroleum Geology 19: 5-40.

Rees, J. 2000. A new Pliensbachian (Early Jurassic) neoselachian shark fauna from southern Sweden. Acta Palaeontologica Polonica 45: 407-424.

Rees, J. 2008. Interrelationships of Mesozoic hybodont sharks as indicated by dental morphology-preliminary results. Acta Geologica Polonica 58(2): 217-221.

Rees, J., and C.J. Underwood. 2002. The status of the shark genus Lissodus Brough 1935, and the position of nominal Lissodus species within the Hybodontoidea (selachii). Journal of Vertebrate Paleontology 22: 471-479.

Rees, J., and C.J. Underwood. 2006. Hybodont sharks from the Middle Jurassic of the Inner Hebrides, Scotland. Transactions of the Royal Society of Edinburgh: Earth Sciences 96: 351-363.

Reif, W.-E. 1978. Types of morphogenesis of the dermal skeleton in fossil sharks. Paläontologische Zeitschrift 52(1/2): 110-128.

Rieppel, O., R. Kindlimann, and H. Bucher. 1996. A new fossil fish fauna from the Middle Triassic (Anisian) of North-Western Nevada. In Mesozoic fishes-systematics and paleoecology, ed. G. Arratia, and G. Viohl, 501-512. München: Verlag Dr. Friedrich Pfeil.

Sattayarak, N. 1983. Review of the continental Mesozoic stratigraphy of Thailand. In Workshop on Stratigraphic Correlation of Thailand and Malaysia, ed. Geological Society of Thailand and Geological Society of Malaysia, 127-148. Bangkok/Kuala Lumpur: Geological Society of Thailand and Geological Society of Malaysia.

Shang, Q., G. Cuny, and L. Chen. 2008. Early Middle Jurassic vertebrate microremains from the three Gorges area, Southern China. Historical Biology 20(2): 87-99.
Srisuk, P. 2002. Vertebrates of the Wang Din So locality (Phu Kradung Formation, Late Jurassic). Bulletin of the Srisuk's House Museum, Series A (Paleontology) 4(2): 24-53.

Stensiö, E. 1921. Triassic fishes from Spitzbergen, part I. Vienna: Adolf Holzhausen.

Tanimoto, M., and S. Tanaka. 1998. Heteroptychodus sp. (Chondrichthyes) from the Lower Cretaceous Matsuo Group of Arashima, Toba City, Mie Prefecture, Southwest Japan. Chigakukenkyu 47: 37-40.

Tong, H., J. Claude, V. Suteethorn, W. Naksri, and E. Buffetaut. 2009a. Turtle assemblages of the Khorat Group (Late JurassicEarly Cretaceous) of NE Thailand and their palaeobiogeographical significance. In Late Palaeozoic and Mesozoic Ecosystems in SE Asia, vol 315, eds. E. Buffetaut, G. Cuny, J. Le Loeuff, and V. Suteethorn, 141-152. London: Geological Society Special Publications.

Tong, H., J. Claude, W. Naksri, V. Suteethorn, E. Buffetaut, S. Khansubha, K. Wongko, and P. Yuangdetkla. 2009b. Basilochelys macrobios n. gen. and n. sp., a large cryptodiran turtle from the Phu Kradung Formation (latest Jurassic-earliest Cretaceous) of the Khorat Plateau, NE Thailand. In Late Palaeozoic and Mesozoic Ecosystems in SE Asia, vol 315, eds. E. Buffetaut, G. Cuny, J. Le Loeuff, and V. Suteethorn, 153-173. London: Geological Society Special Publications.

Underwood, C.J., and J. Rees. 2002. Selachian faunas from the lowermost Cretaceous Purbeck Group of Dorset, Southern England. Special Papers in Palaeontology 68: 83-101.

Wang, N.-Z. 1977. The Jurassic fish fossils from Liling-Hengyong region of Hunan and its biostratigraphical significance. Vertebrata PalAsiatica 15: 233-243.

Xue, X.-X. 1980. New materials of Hybodontidae in Gansu and Shaanxi. Vertebrata PalAsiatica 18: 9-15.

Yabe, H., and T. Obata. 1930. On some fossil fishes from the Cretaceous of Japan. Japanese Journal of Geology and Geography 8: 1-8. 